\title{
Effectiveness and safety of glucocorticoids to treat COVID-19: a rapid review and meta-analysis
}

\author{
Shuya Lu ${ }^{1,2,3 \#}$, Qi Zhou, ${ }^{3,4 \#}$, Liping Huang ${ }^{5,6,7 \#}$, Qianling Shi, ${ }^{3,4}$ Siya Zhao ${ }^{8}$, Zijun Wang ${ }^{3}$, Weiguo Li $^{5,6,7}$, \\ Yuyi Tang ${ }^{5,6,7}$, Yanfang $\mathrm{Ma}^{3}$, Xufei Luo, ${ }^{3,8}$, Toshio Fukuoka ${ }^{9,10}$, Hyeong Sik Ahn ${ }^{11,12}$, Myeong Soo Lee ${ }^{13,14}$, \\ Zhengxiu Luo $^{5,6,7}$, Enmei Liu ${ }^{5,6,7}$, Yaolong Chen ${ }^{3,15,16,17}$, Chenyan Zhou ${ }^{1,2}$, Donghong Peng ${ }^{5,6,7}$; on behalf of \\ COVID-19 Evidence and Recommendations Working Group
}

${ }^{1}$ Department of Pediatric, Sichuan Provincial People's Hospital, University of Electronic Science and Technology of China, Chengdu 611731, China; ${ }^{2}$ Chinese Academy of Sciences Sichuan Translational Medicine Research Hospital, Chengdu 610072, China; ${ }^{3}$ Evidence-based Medicine Center, School of Basic Medical Sciences, Lanzhou University, Lanzhou 730000, China; ${ }^{4}$ The First School of Clinical Medicine, Lanzhou University, Lanzhou 730000, China; ${ }^{5}$ Department of Respiratory Medicine, Children's Hospital of Chongqing Medical University, Chongqing 400014, China; ${ }^{6}$ National Clinical Research Center for Child Health and Disorders, Ministry of Education Key Laboratory of Child Development and Disorders, China International Science and Technology Cooperation Base of Child Development and Critical Disorders, Children's Hospital of Chongqing Medical University, Chongqing 400014, China; ${ }^{7}$ Chongqing Key Laboratory of Pediatrics, Chongqing 400014, China; ${ }^{8}$ School of Public Health, Lanzhou University, Lanzhou 730000, China; ${ }^{9}$ Emergency and Critical Care Center, the Department of General Medicine, Department of Research and Medical Education at Kurashiki Central Hospital, Kurashiki, Japan; ${ }^{10}$ Advisory Committee in Cochrane Japan, Tokyo, Japan; ${ }^{11}$ Department of Preventive Medicine, Korea University College of Medicine, Seoul, Korea; ${ }^{12}$ Korea Cochrane Centre, Seoul, Korea; ${ }^{13}$ Korea Institute of Oriental Medicine, Daejeon, Korea; ${ }^{14}$ University of Science and Technology, Daejeon, Korea; ${ }^{15}$ Lanzhou University, an Affiliate of the Cochrane China Network, Lanzhou 730000, China; ${ }^{16}$ Chinese GRADE Center, Lanzhou 730000, China; ${ }^{17}$ Key Laboratory of Evidence Based Medicine and Knowledge Translation of Gansu Province, Lanzhou University, Lanzhou 730000, China

Contributions: (I) Conception and design: S Lu, Q Zhou, L Huang; (II) Administrative support: Y Chen; (III) Provision of study materials or patients: S Lu, L Huang, Q Zhou; (IV) Collection and assembly of data: S Lu, Q Zhou, Q Shi; (V) Data analysis and interpretation: Q Zhou, S Lu, S Zhao; (VI) Manuscript writing: All authors; (VII) Final approval of manuscript: All authors.

"These authors contributed equally to this work.

Correspondence to: Chenyan Zhou. Department of Pediatric, Sichuan Provincial People's Hospital, University of Electronic Science and Technology of China, Chengdu 611731, China. Email: dian_z@163.com; Donghong Peng. Department of Respiratory Medicine, Children’s Hospital of Chongqing Medical University, Chongqing 400014, China. Email: 400713@hospital.cqmu.edu.cn.

Background: Glucocorticoids are widely used in the treatment of various pulmonary inflammatory diseases, but they are also often accompanied by significant adverse reactions. Published guidelines point out that low dose and short duration systemic glucocorticoid therapy may be considered for patients with rapidly progressing coronavirus disease 2019 (COVID-19) while the evidence is still limited.

Methods: We comprehensively searched electronic databases and supplemented the screening by conducting a manual search. We included randomized controlled trials (RCTs) and cohort studies evaluating the effectiveness and safety of glucocorticoids in children and adults with COVID-19, severe acute respiratory syndrome (SARS) and Middle East respiratory syndrome (MERS), and conducted meta-analyses of the main indicators that were identified in the studies.

Results: Our search retrieved 23 studies, including one RCT and 22 cohort studies, with a total of 13,815 patients. In adults with COVID-19, the use of systemic glucocorticoid did not reduce mortality [risk ratio $(\mathrm{RR})=2.00,95 \%$ confidence interval $(\mathrm{CI}): 0.69$ to $5.75, \mathrm{I}^{2}=90.9 \%$ ] or the duration of lung inflammation [weighted mean difference $(\mathrm{WMD})=-1$ days, 95\% CI: -2.91 to 0.91 ], while a significant reduction was found in the duration of fever (WMD $=-3.23$ days, 95\% CI: -3.56 to -2.90 ). In patients with SARS, glucocorticoids also did not reduce the mortality ( $\mathrm{RR}=1.52,95 \% \mathrm{CI}: 0.89$ to $2.60, \mathrm{I}^{2}=84.6 \%$ ), duration of fever (WMD $=0.82$ days, $95 \%$ CI: -2.88 to $4.52, \mathrm{I}^{2}=97.9 \%$ ) or duration of lung inflammation absorption (WMD $=0.95$ days, $95 \% \mathrm{CI}:-7.57$ to $9.48, \mathrm{I}^{2}=94.6 \%$ ). The use of systemic glucocorticoid therapy prolonged the duration of hospital stay in all patients (COVID-19, SARS and MERS). 
Conclusions: Glucocorticoid therapy was found to reduce the duration of fever, but not mortality, duration of hospitalization or lung inflammation absorption. Long-term use of high-dose glucocorticoids increased the risk of adverse reactions such as coinfections, so routine use of systemic glucocorticoids for patients with COVID-19 cannot be recommend.

Keywords: Coronavirus disease 2019 (COVID-19); glucocorticoids; meta-analysis; rapid review

Submitted Apr 14, 2020. Accepted for publication Apr 30, 2020.

doi: 10.21037/atm-20-3307

View this article at: http://dx.doi.org/10.21037/atm-20-3307

\section{Introduction}

An infectious disease caused by a previously unknown type of coronavirus, the severe acute respiratory syndrome coronavirus 2 (SARS-CoV-2), emerged at the end of December 2019 and has posed a major challenge to the public health worldwide (1). The World Health Organization (WHO) officially named the disease as Coronavirus Disease 2019 (COVID-19) on February 11, 2020 (2). On March 11, 2020, the WHO declared COVID-19 as a global pandemic (3). Globally, as of 2:00 am CEST, 12 April 2020, there have been 1,699,595 confirmed cases of COVID-19, including 106,138 deaths, reported to WHO (4).

At present, there are no specific drugs for the prevention and treatment of COVID-19, and symptomatic supportive treatment remains the most effective method of care. Full-genome sequencing and phylogenetic analyses have indicated SARS-CoV-2 is a distinct clade of betacoronaviruses, related to the Middle East respiratory syndrome coronavirus (MERS-CoV) and SARS-CoV. Therefore, the management of COVID-19 can benefit from experience from the SARS and MERS epidemics (5). Glucocorticoids were commonly used for the treatment of SARS and MERS especially in critically ill people $(6,7)$, and are also widely used in the treatment of COVID-19.

There are conflicting opinions about the use of glucocorticoids to treat patients with COVID-19. It is suggested that current clinical evidence does not support the use of glucocorticoids, which may cause several side effects $(8,9)$. However, clinicians who are on the front line of the epidemic have proposed that short-term glucocorticoid therapy with small or medium dose could be beneficial for patients with severe conditions (10). The current guidelines on COVID-19 are also inconsistent about the use of glucocorticoids. Some guidelines suggested trying shortterm therapy with medium or small doses of glucocorticoids for patients with rapid or severe disease progression, but according to the WHO guidelines glucocorticoids should only be used under clinical trial conditions (11-13). Effective evidence related to glucocorticoilds to treat COVID-19 is still lacking.

Therefore, the purpose of this study is to systematically retrieve and summarize the current evidence of the effectiveness and safety of glucocorticoid therapy for patients with COVID-19, aiming to provide the best decision-making basis for the prevention and control of the COVID-19 epidemic. We present the following article in accordance with the PRISMA reporting checklist (available at http://dx.doi.org/10.21037/atm-20-3307).

\section{Methods}

\section{Search strategy}

Two experienced librarians searched the following databases from January 1st, 2003 to March 31th, 2020: The Cochrane library, MEDLINE (via PubMed), Embase, Web of Science, CBM (China Biology Medicine), CNKI (China National Knowledge Infrastructure), and Wanfang Data. We used the following search: ("COVID-19" OR "SARS-CoV-2" OR "2019 novel coronavirus" OR "2019nCoV" OR "MERS" OR "SARS" OR "Severe Acute Respiratory Syndrome" OR "Middle East Respiratory Syndrome Coronavirus" OR "Influenza") AND ("adrenal cortex hormones" OR "betamethasone valerate" OR "glucocorticoids" OR "methylprednisolone" OR "Cortisone" OR "Dexamethasone" OR "Cortodoxone" OR "Hydrocortisone"). We also searched clinical trial registry platforms (the World Health Organization Clinical Trials Registry Platform, US National Institutes of Health Trials Register and the International Standard Randomized Controlled Trial Number (ISRCTN) Register), Google Scholar (https://scholar.google.nl/) and preprint platforms BioRxiv (https://www.biorxiv.org/), MedRxiv (https:// www.medrxiv.org/) and SSRN (https://www.ssrn.com/ 
index.cfm/en/). In addition, we searched the reference lists of the identified systematic reviews to find further potential studies, and supplemented screening Google Scholar by conducting a manual search every day before submission. The search strategy was constructed with the assistance of a specialist in information retrieval (14). The details of the search strategy can be found in the Supplementary material 1 .

\section{Inclusion and exclusion criteria}

We included all studies on glucocorticoid therapy for patients diagnosed with COVID-19, SARS or MERS, without restricting the diagnostic criteria. We included randomized controlled trials (RCTs) and cohort studies comparing glucocorticoid therapy versus placebo or comparing a combination of glucocorticoids and symptomatic treatment with symptomatic treatment alone. The primary outcome of interest was mortality, and secondary outcomes included duration of lung inflammation absorption, duration of hospital stay, duration of fever, and other adverse effects like coinfections (bacterial or fungal infections), kaliopenia, and osteonecrosis of femoral head (ONFH).

We excluded conference abstracts, articles written in languages other than English or Chinese and studies where we could not retrieve the full text or essential data were missing. All the reasons for exclusion of ineligible studies were recorded, and the process of study selection was documented using a PRISMA flow diagram (15).

\section{Study selection}

After eliminating duplicates, two researchers ( $\mathrm{S} \mathrm{Lu}$ and $\mathrm{L}$ Huang) independently screened the literature in two steps using the EndNote software. In the first step, all titles and abstracts were screened using pre-defined criteria to exclude irrelevant articles. In the second step, full-texts of the potentially eligible and unclear studies were reviewed to decide about final inclusion. Disagreements were discussed or solved with a third researcher (Q Shi). All the reasons for exclusion of ineligible studies were recorded, and the process of study selection was documented using a PRISMA flow diagram (16).

\section{Data extraction}

Two researchers (S Lu and Q Zhou) independently extracted the data and information from all included studies by using a standardized data collection form. Extracted data included (I) basic information: first author, publication year, and the type of study design; (II) participants: disease, severity of disease, age distribution, and total number of patients; (III) details of the intervention and control groups: type, dosage and treatment course of glucocorticoid therapy; and (IV) outcomes: for dichotomous data, we abstracted the number of events and total number of patients per group; and for continuous data, we abstracted the means, standard deviations (SD), and the total number of patients per group. For data that were missing or reported in unusable way, we reported the findings descriptively.

\section{Risk of bias assessment}

Two researchers (S Lu and S Zhao) independently assessed the potential bias in each included study, and discrepancies were resolved by discussion or consulting a third researcher (Q Shi). We assessed the risk of bias in RCTs using the Cochrane risk-of-bias tool (17), which consists of seven domains: random sequence generation, allocation concealment, blinding of participants and personnel, blinding of outcome assessment, incomplete outcome data, selective outcome reporting, and other bias. Each domain was graded as "Low", "Unclear", or "High". For cohort studies, we used the Newcastle-Ottawa Scale (NOS) (18), which contains eight domains: representativeness of exposure cohorts, selection of non-exposure cohorts, determination of exposure, outcome events that did not occur before study initiation, comparability of cohort based on design or analysis, assessment of outcome events, adequacy of follow-up time, and completeness of follow-up.

\section{Quality of the evidence}

Two researchers (Q Zhou and Q Shi) assessed the quality of evidence independently using the Grading of Recommendations Assessment, Development and Evaluation (GRADE) tool $(19,20)$. We produced a "Summary of Findings" table using the GRADEpro software. The quality of evidence can be downgraded based on five factors (study limitations, consistency of effect, imprecision, indirectness and publication bias) and upgraded based on three factors (large magnitude of effect, dose-response relation and plausible confounders or biases) (21-26). The quality of evidence of each outcome is then classified as "high", "moderate", "low" or "very low". 


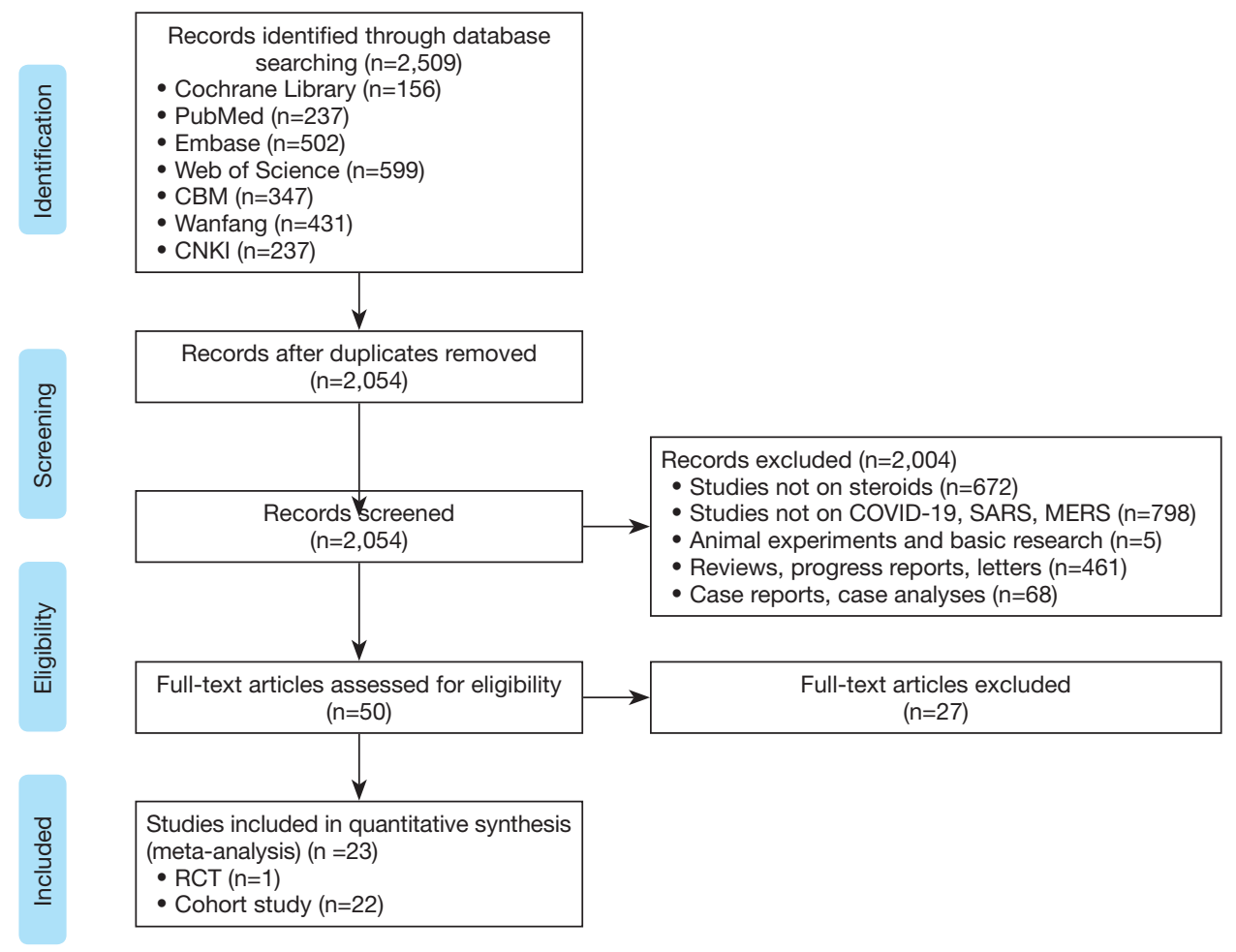

Figure 1 PRISMA flow chart. RCT, randomized controlled trial.

\section{Data synthesis}

We conducted meta-analyses by using Stata 14 software (Stata Corp LLC). For dichotomous data, we calculated risk ratios (RRs) with $95 \%$ confidence intervals (CIs); for continuous data, we calculated weighted mean differences (WMDs) with 95\% CI. Missing data were dealt with according to the Cochrane Handbook for Systematic Reviews of Interventions (27). As clinical and methodological heterogeneity in study design, characteristics of participants, interventions and outcome measures was expected, we used random-effects models (28). Two-sided $\mathrm{P}$ values $<0.05$ were considered statistically significant. Statistical heterogeneity was assessed with the $\mathrm{I}^{2}$ statistic, $>50 \%$ indicating substantial heterogeneity. If we detected heterogeneity, we performed subgroup analyses by the severity of the disease or the age of patients, and also considered sensitivity analyses where one study was excluded at a time. Egger test was used to assess publication bias (15). Each comparison is presented by the name of the first author and the year of publication.

As COVID-19 is a public health emergency of international concern and the situation is evolving rapidly, our study was not registered in order to speed up the process.

\section{Results}

\section{Basic characteristics}

The rapid review identified 2,509 publications, of which 23 studies (one RCT and 22 cohort studies) (29-51) met our inclusion criteria and were included. The literature screening process is shown in Figure 1. One study included adult patients with severe MERS, 17 studies included patients with SARS, and the remaining five studies were on patients with COVID-19 (Table 1). Due to the insufficient representativeness and follow-up time, only three articles scored higher than 6 out of 9 points. The methodological quality of included cohort studies was poor. The risk of bias of included RCT was unclear because of unclear risks of selection bias, detection bias and reporting bias (Tables 2,3).

\section{Meta-analyses}

Mortality was assessed in 13 cohort studies (4 on COVID-19, 8 on SARS, 1 on severe MERS) (29-41) with a total of 11,211 patients. The use of systemic glucocorticoid did not reduce the risk of death in COVID-19 ( $\mathrm{RR}=2.0,95 \%$ CI: 0.7 to 5.8 , $\mathrm{I}^{2}=90.9 \%$ ) or SARS patients ( $\mathrm{RR}=1.5,95 \%$ CI: 0.9 to 2.6 , 


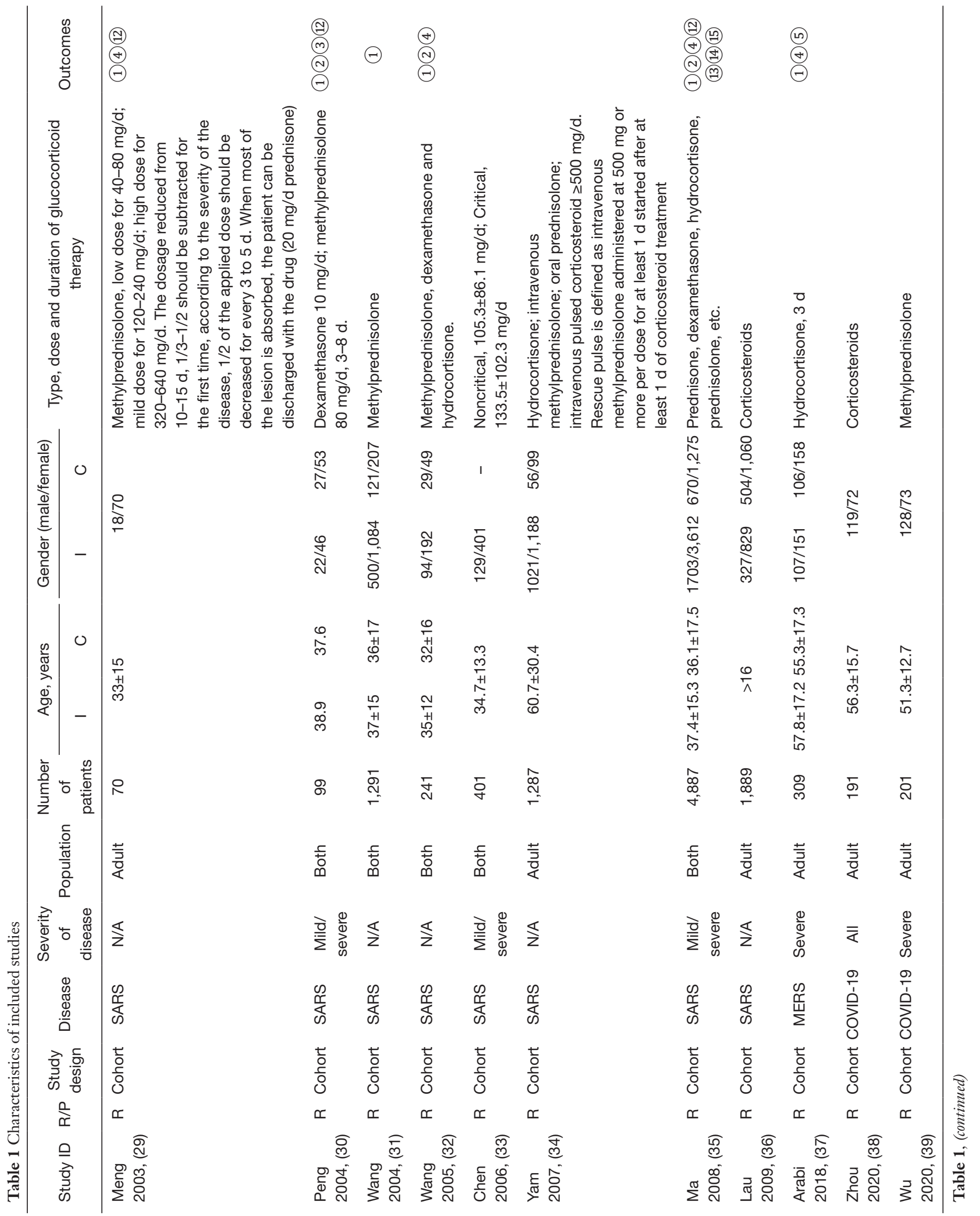




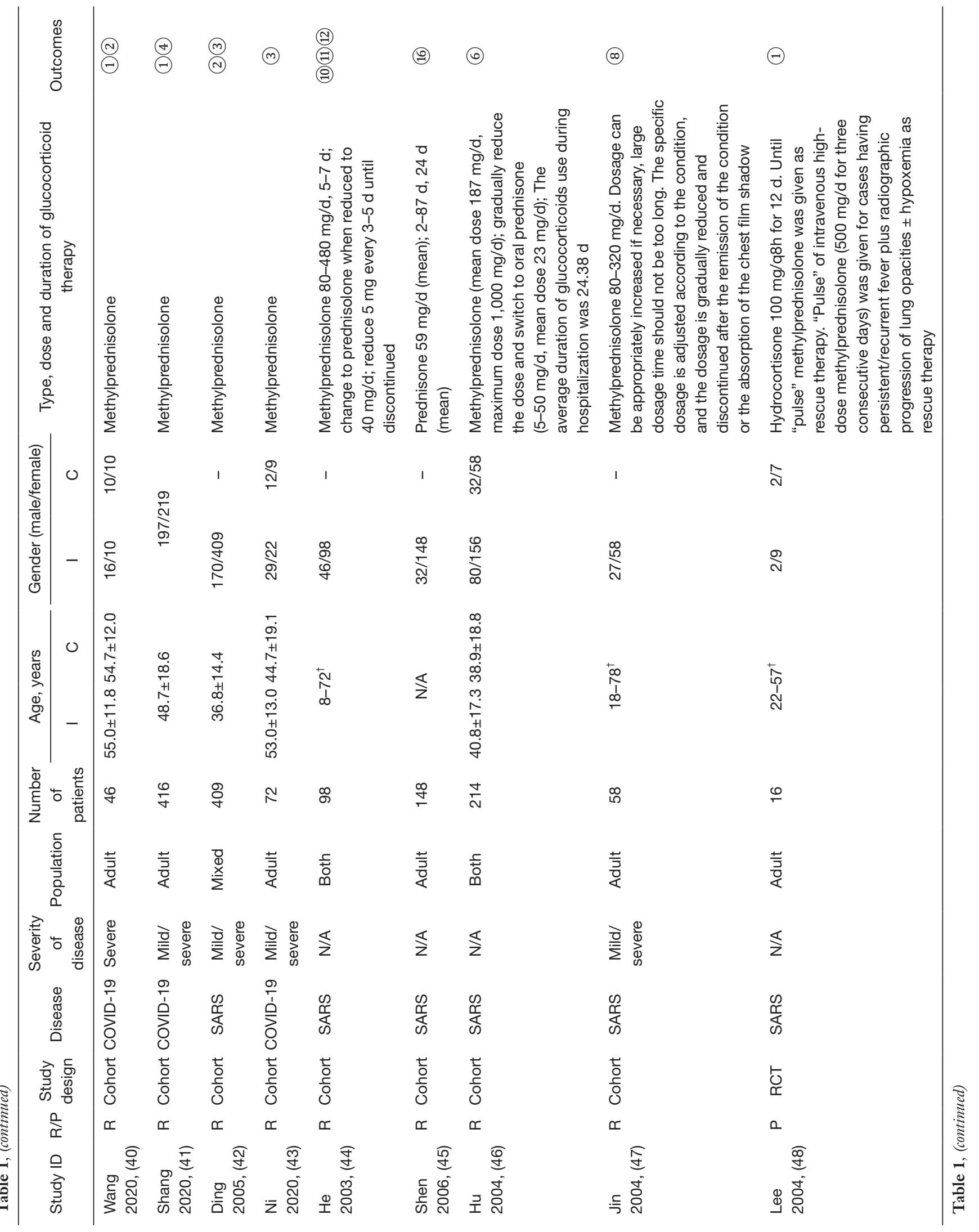




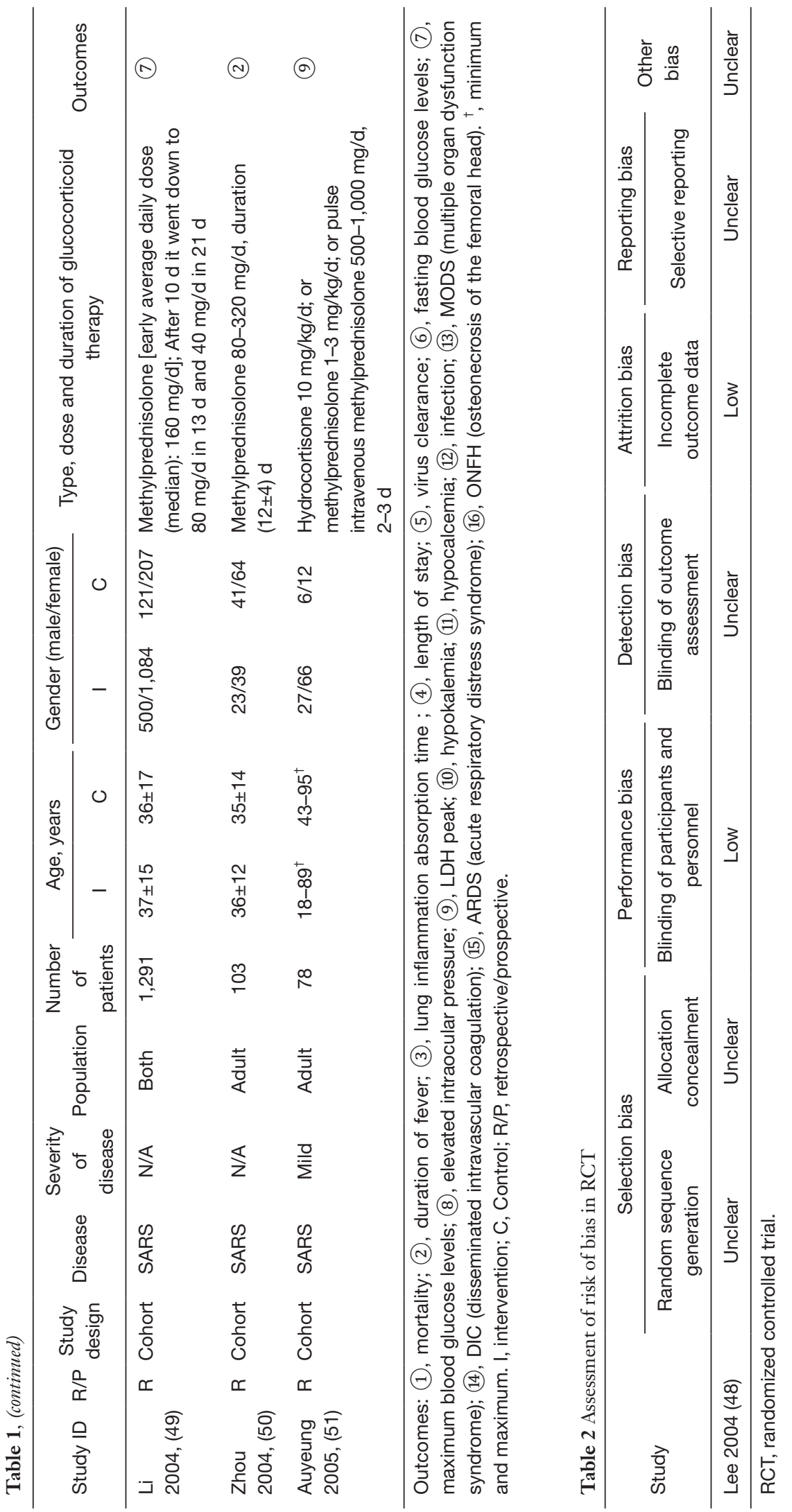




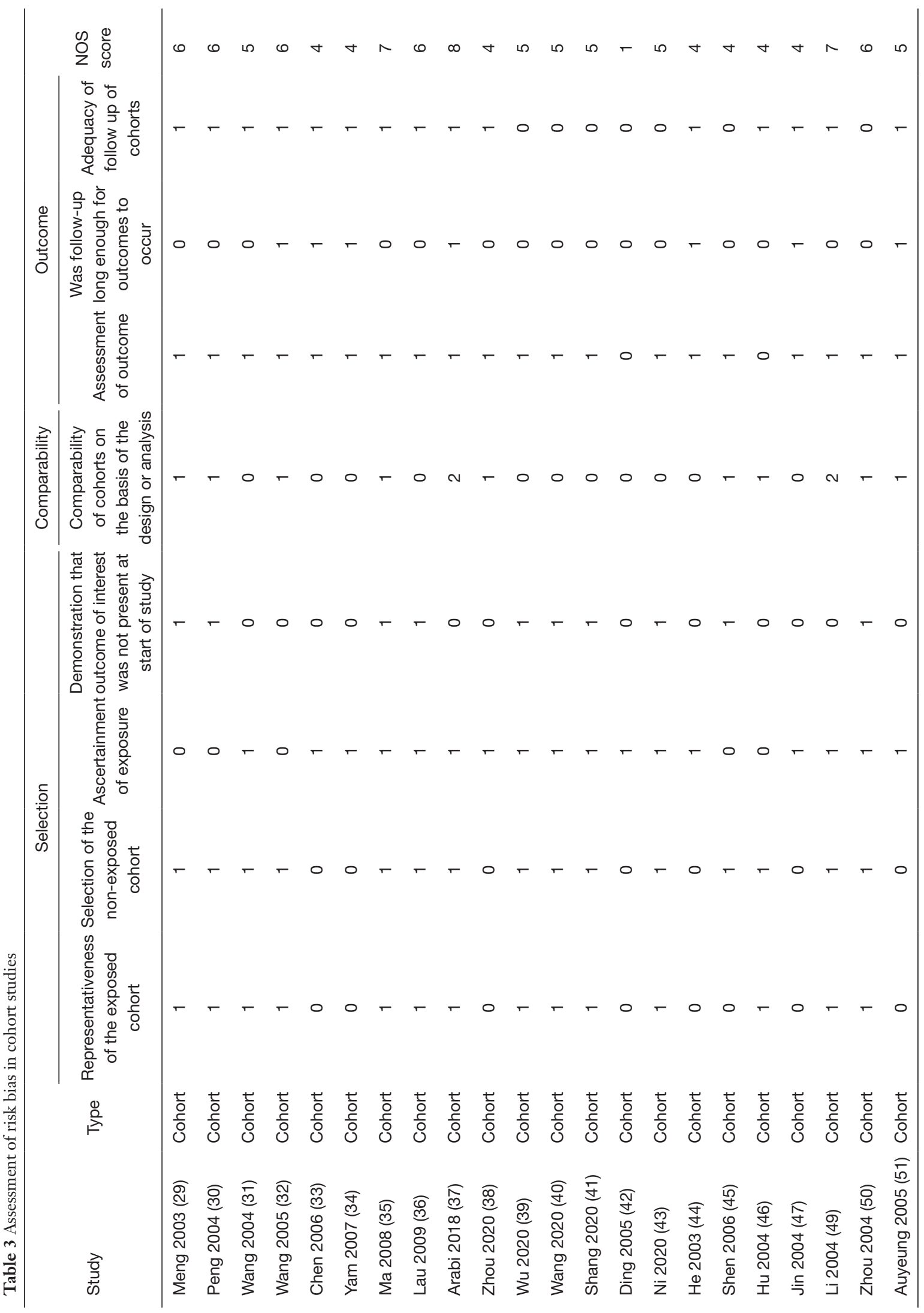




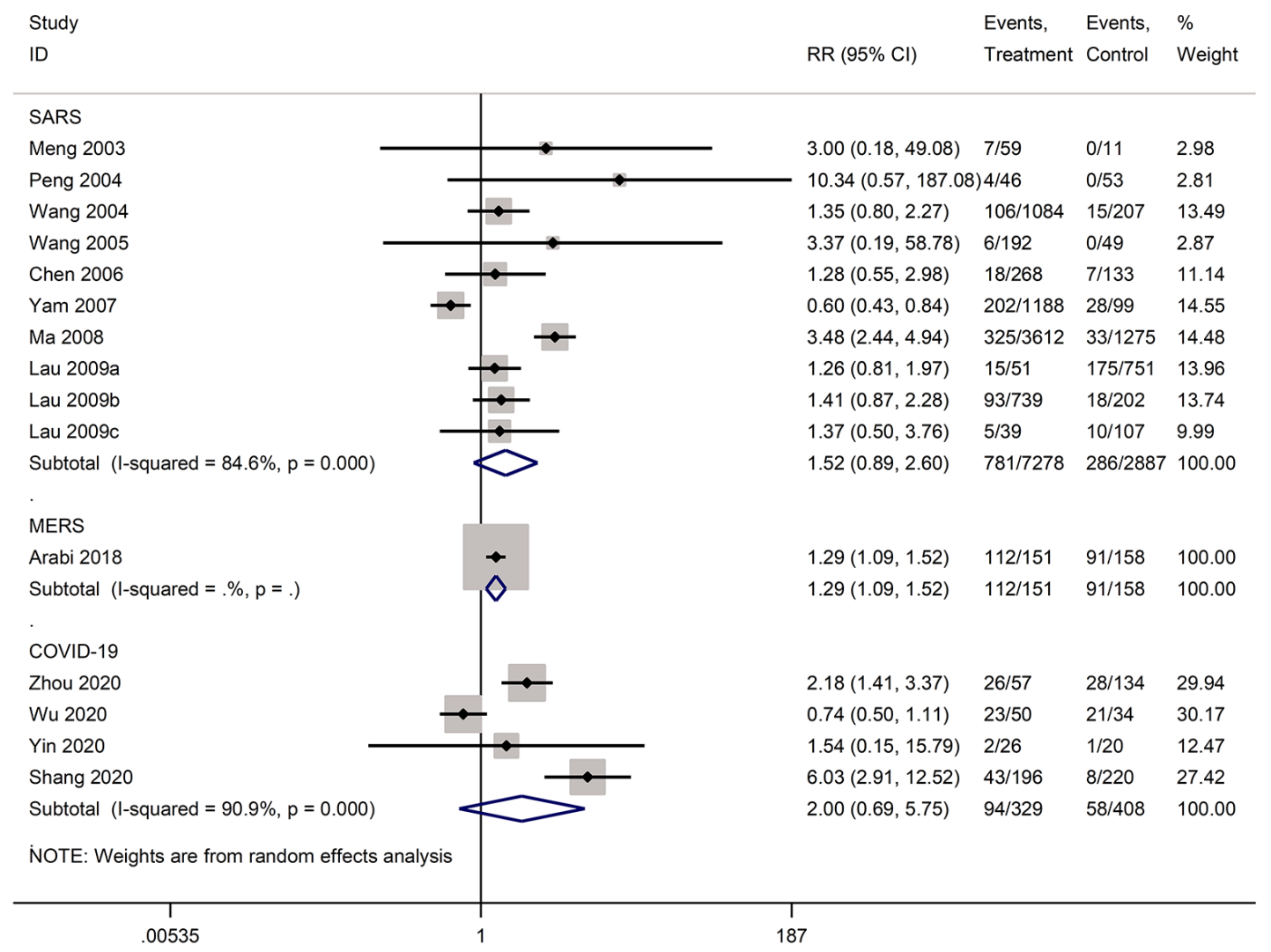

Figure 2 Relative risk of death in patients receiving versus not receiving glucocorticoid therapy: all patients. RR, risk ratio; CI, confidence interval.

$\left.\mathrm{I}^{2}=84.6 \%\right)$. Subgroup analyses showed that glucocorticoids also did not reduce the risk of death in severe cases of SARS ( $\mathrm{RR}=1.3,95 \%$ CI: 0.5 to $3.3, \mathrm{I}^{2}=67.4 \%$ ) or in adults (RR $=1.1,95 \%$ CI: 0.7 to $\left.1.8, \mathrm{I}^{2}=68.7 \%\right)$. In mild cases of SARS glucocorticoids even increased the risk of death $(\mathrm{RR}=3.6$, 95\% CI: 1.9 to 6.9). In adult patients with MERS, the use of glucocorticoid increased mortality ( $\mathrm{RR}=1.3,95 \% \mathrm{CI}$ : 1.1 to 1.5) (Figures 2-4).

Five cohort studies with a total of 4,709 patients assessed the duration of fever in COVID-19 (one study) and SARS (four studies) patients $(30,32,35,40,42)$. The duration of fever was significantly lower in COVID-19 patients who received glucocorticoid treatment than in patients who received no glucocorticoid treatment (WMD $=-3.2 \mathrm{~d}, 95 \%$ CI: -3.6 to -2.9 ), while for SARS patients there was no difference (WMD $=0.8 \mathrm{~d}$, 95\% CI: -2.9 to $4.5, \mathrm{I}^{2}=97.9 \%$ ). Subgroup analysis showed that glucocorticoid use did not shorten the duration of fever neither in patients with severe SARS (WMD $=-1.1 \mathrm{~d}, 95 \% \mathrm{CI}:-4.9$ to $2.7, \mathrm{I}^{2}=58.3 \%$ ) nor in patients with mild SARS (WMD $=0.5 \mathrm{~d}, 95 \% \mathrm{CI}:-4.2$ to

\section{$\left.5.1, \mathrm{I}^{2}=95.1 \%\right)$ (Figures 5,6 ).}

Three cohort studies assessed the duration of lung inflammation absorption in patients with COVID-19 (one study) and SARS (two studies) $(30,42,43)$. No difference between patients who received or did not receive glucocorticoid treatment was found in neither COVID-19 (WMD $=-1.0$ d, 95\% CI: -2.9 to 0.9 ) nor SARS (WMD $=1.0$ d, $95 \%$ CI: -7.6 to $\left.9.5, I^{2}=94.6 \%\right)$ patients. Subgroup analyses showed that using glucocorticoids did not shorten the absorption time of lung inflammation in patients with severe SARS regardless of severity (WMD $=0.4 \mathrm{~d}, 95 \% \mathrm{CI}$ : -4.2 to $5.1, \mathrm{I}^{2}=0 \%$ ), or with mild SARS (WMD $=1.3 \mathrm{~d}, 95 \%$ CI: -8.7 to $11.3, \mathrm{I}^{2}=95.5 \%$ ) (Figures 7,8 ).

Five cohort studies (one on COVID-19, three on SARS, one on severe MERS) with a total of 5,872 patients assessed the duration of hospital stay $(29,31,35,37,41)$. Patients treated with glucocorticoids stayed longer in the hospital than patients who did not receive glucocorticoids (COVID-19: $W M D=2.4$ d, $95 \%$ CI: 1.4 to $3.4, \mathrm{I}^{2}=0.0 \%$; SARS: $\mathrm{WMD}=6.8 \mathrm{~d}, 95 \% \mathrm{CI}: 1.5$ to $12.2, \mathrm{I}^{2}=94.2 \%$; 


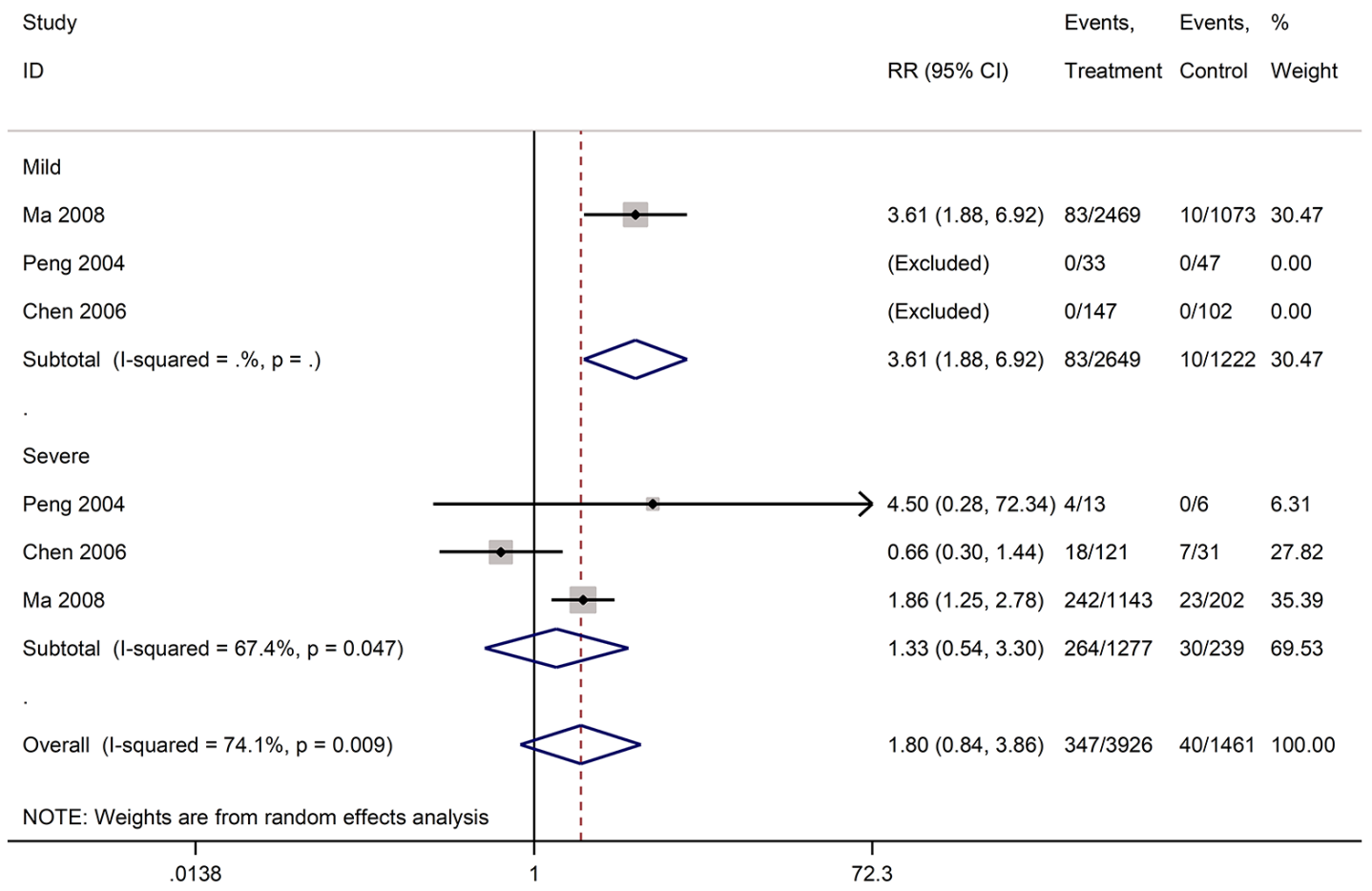

Figure 3 Relative risk of death in patients receiving versus not receiving glucocorticoid therapy: subgroup analyses of patients with mild and severe SARS. RR, risk ratio; CI, confidence interval.

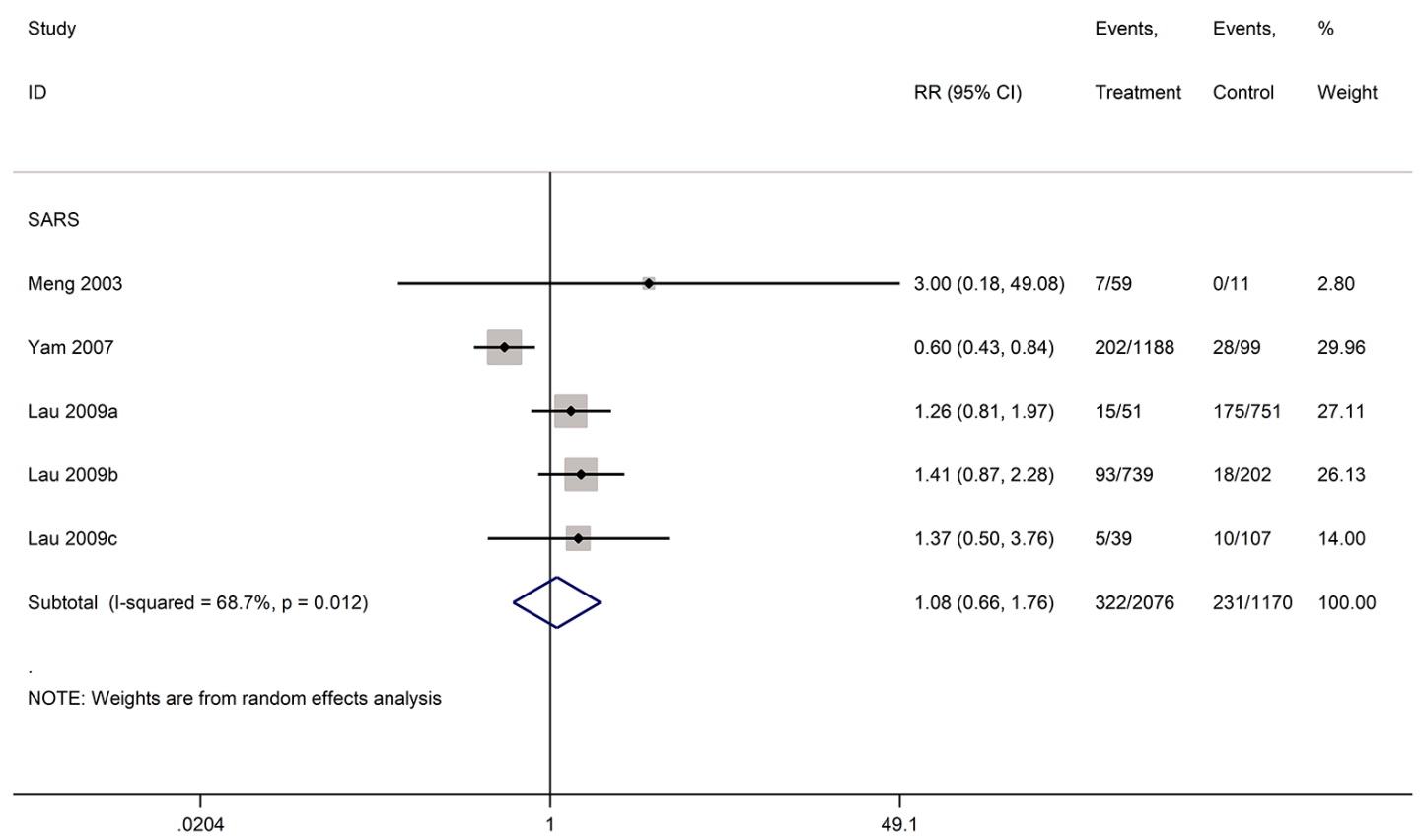

Figure 4 Relative risk of death in patients receiving versus not receiving glucocorticoid therapy: subgroup analyses of adult patients with SARS. RR, risk ratio; CI, confidence interval. 


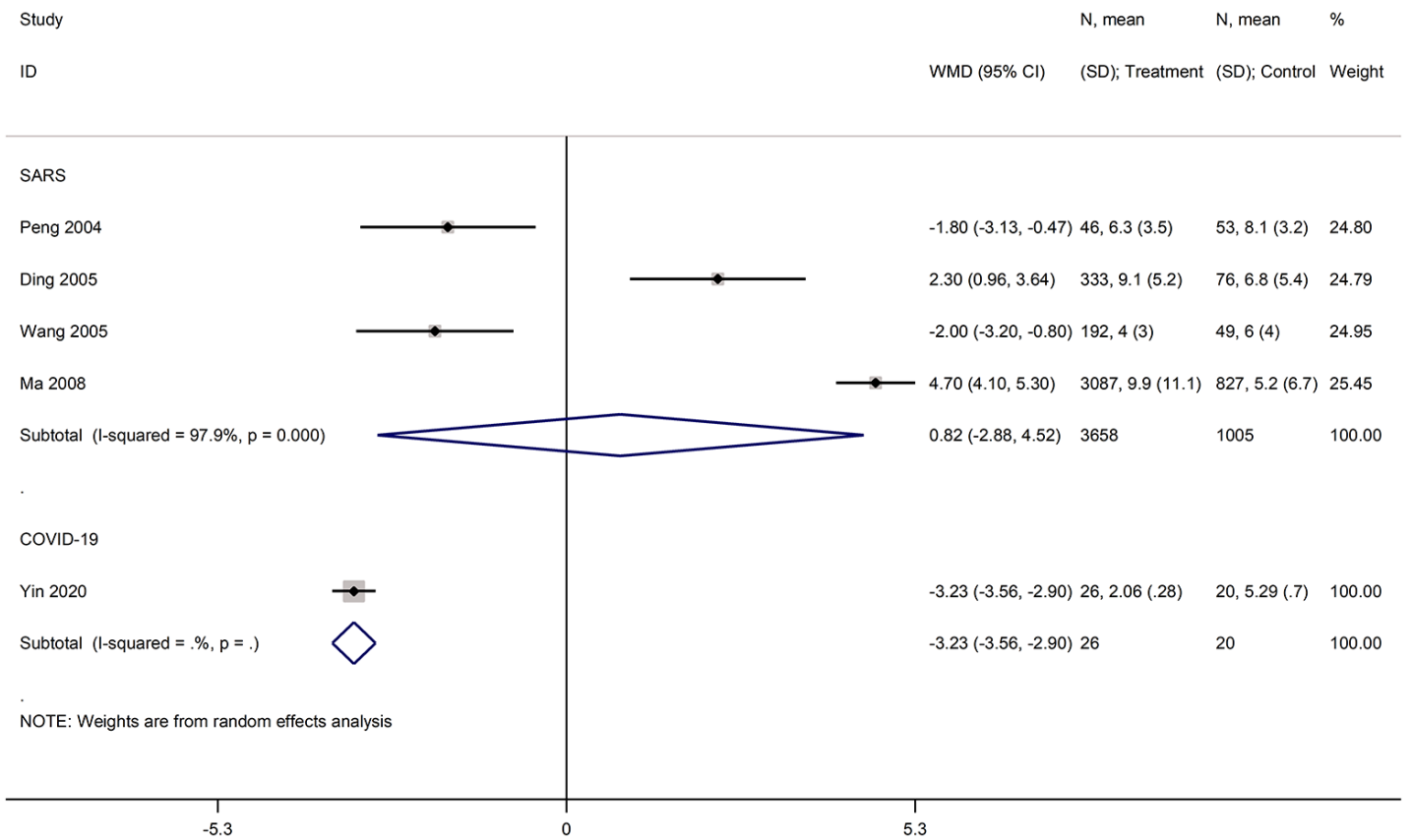

Figure 5 Duration of fever in patients receiving versus not receiving glucocorticoid therapy: all patients. WMD, weighted mean difference; CI, confidence interval; SD, standard deviation.

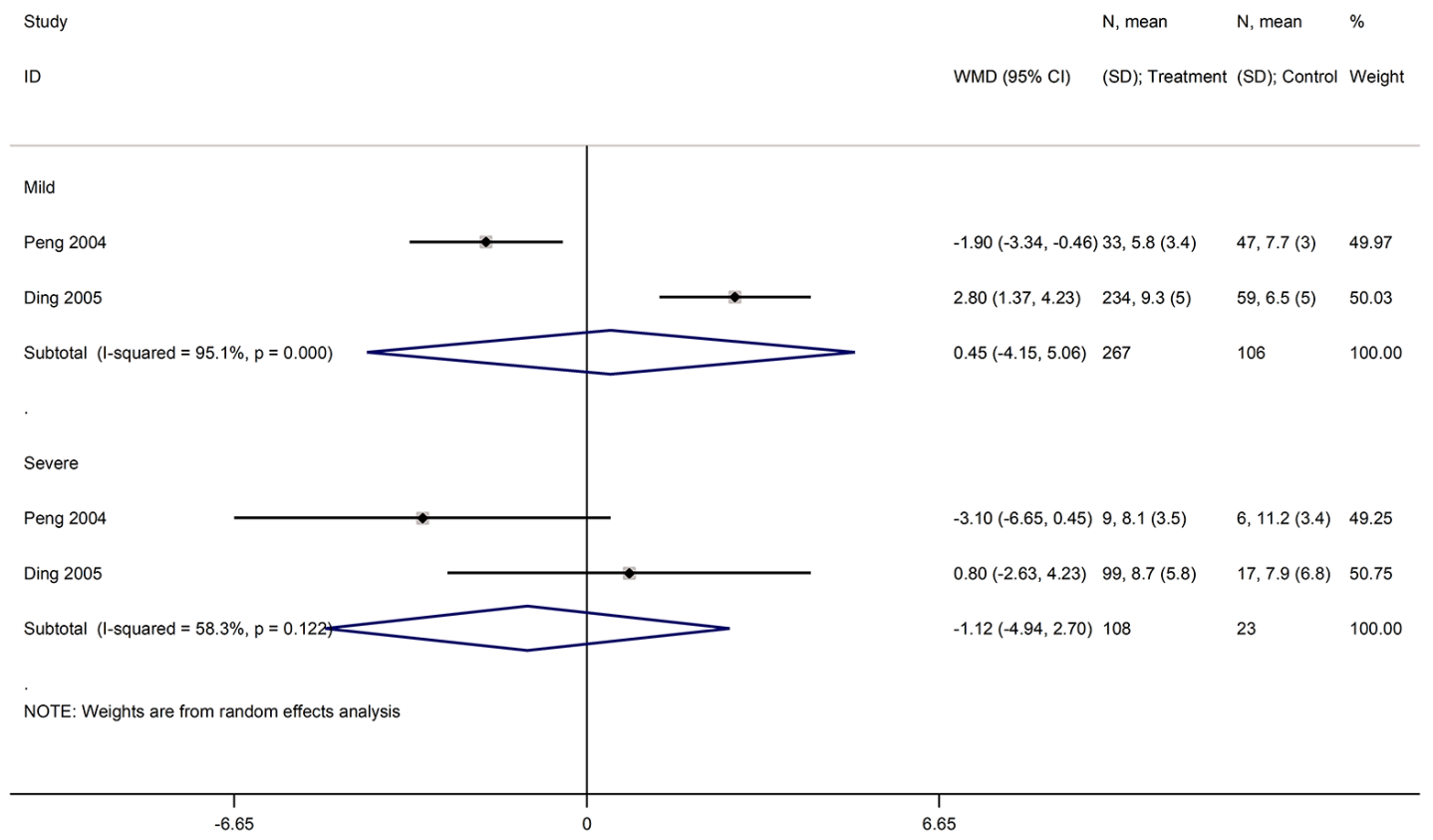

Figure 6 Duration of fever in patients receiving versus not receiving glucocorticoid therapy: subgroup analyses of patients with mild and severe SARS. WMD, weighted mean difference; CI, confidence interval; SD, standard deviation. 


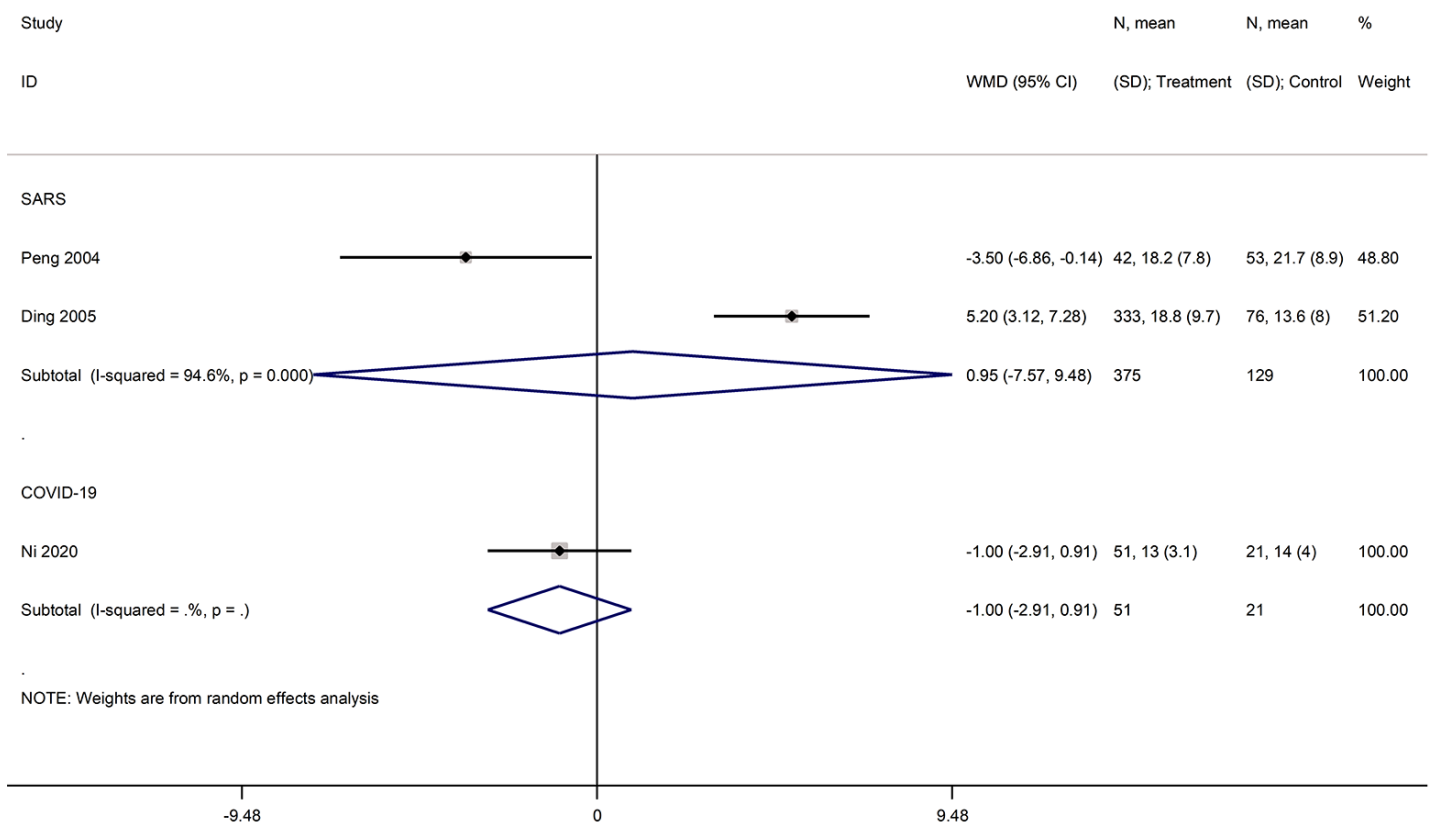

Figure 7 Lung inflammation absorption time in patients receiving versus not receiving glucocorticoid therapy: all patients. WMD, weighted mean difference; CI, confidence interval; SD, standard deviation.

Study

ID
$\mathrm{N}$, mean $\quad \mathrm{N}$, mean $\quad \%$

WMD $(95 \% \mathrm{Cl}) \quad(\mathrm{SD})$; Treatment $(\mathrm{SD})$; Control Weight

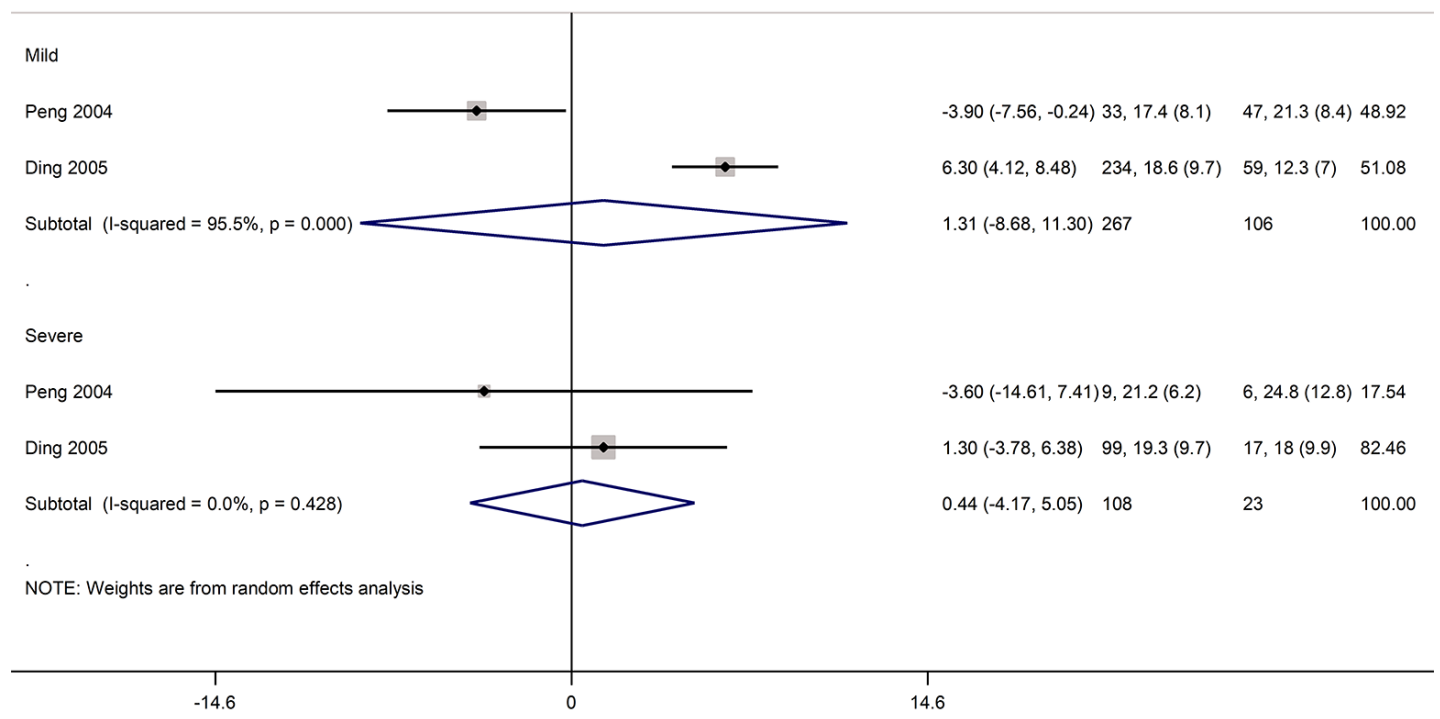

Figure 8 Lung inflammation absorption time in patients receiving versus not receiving glucocorticoid therapy: subgroup analyses of patients with mild and severe SARS. WMD, weighted mean difference; CI, confidence interval; SD, standard deviation. 


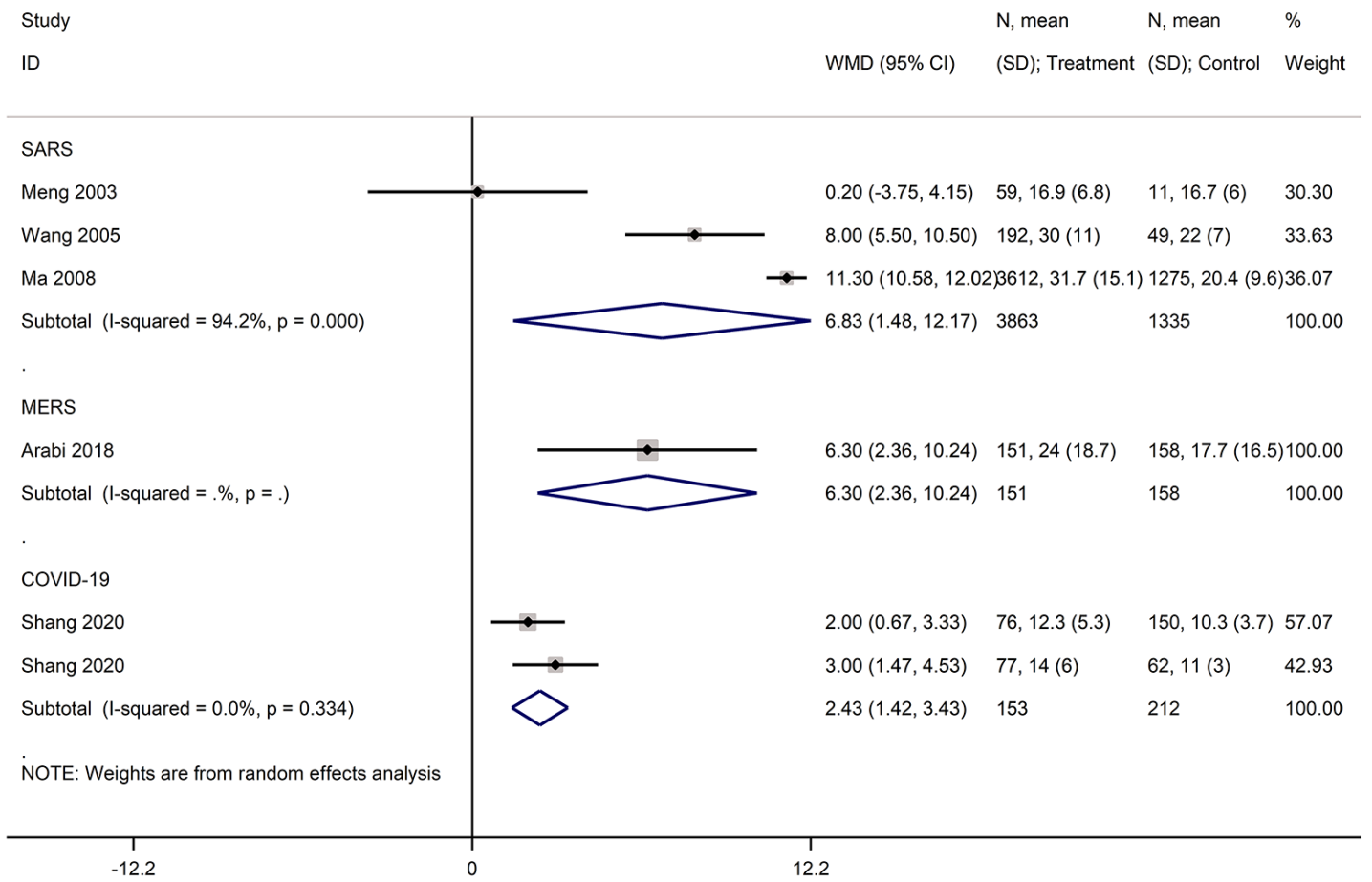

Figure 9 Length of stay in patients receiving versus not receiving glucocorticoid therapy: all patients. WMD, weighted mean difference; CI, confidence interval; SD, standard deviation.

MERS: WMD =6.3 d, 95\% CI: 2.4 to 10.2) (Figure 9).

Five cohort studies with a total of 5,302 patients assessed the adverse outcomes in patients with SARS $(29,30,35,44,45)$. Glucocorticoid use increased the risk of coinfections (bacterial or fungal) ( $\mathrm{RR}=3.5,95 \% \mathrm{CI}: 2.3$ to $\left.5.3, \mathrm{I}^{2}=0 \%\right)$, multiple organ dysfunction syndrome (MODS) ( $\mathrm{RR}=3.9,95 \%$ CI: 2.1 to 6.9 ), and acute respiratory distress syndrome (ARDS) (RR =6.1, 95\% CI: 3.2 to 11.5), while no significant association on disseminated intravascular coagulation (DIC), hypokalemia, hypocalcemia and ONFH was found (Figure 10).

\section{Quality of evidence}

The quality of evidence on the results on mortality in COVID-19 and SARS studies, of very low quality, and in MERS studies of low quality (Tables 4-6).

\section{Sensitivity analysis}

Heterogeneity among studies on SARS assessing mortality was significant $\left(\mathrm{I}^{2}=84.6 \%\right)$. Heterogeneity in studies of mortality in SARS patients was reduced to $67.4 \%$ in the subgroup analysis of severe cases, and to $68.7 \%$ in the subgroup analysis of adults. Therefore, disease severity and age are probably the main sources of heterogeneity in the meta-analysis of mortality. We conducted a sensitivity analysis on the on the SARS mortality by omitting one study at a time. Two studies had a significant impact on the results of the meta-analysis $(34,35)$ (Figure 11). The dosing of glucocorticoids was different in the study by Yam et al. than in other studies, so the high heterogeneity in the metaanalysis on mortality may be at least partly caused by the different dosing (34).

\section{Publication bias}

We assessed publication bias was for the eight studies on SARS mortality. The Egger regression test showed that publication bias was unlikely $(\mathrm{P}=0.619)$ (Figure 12).

\section{Discussion}

Our study identified direct evidence on the clinical efficacy of glucocorticoid therapy for five difference outcomes in adults with COVID-19. Evidence of low to very low- 


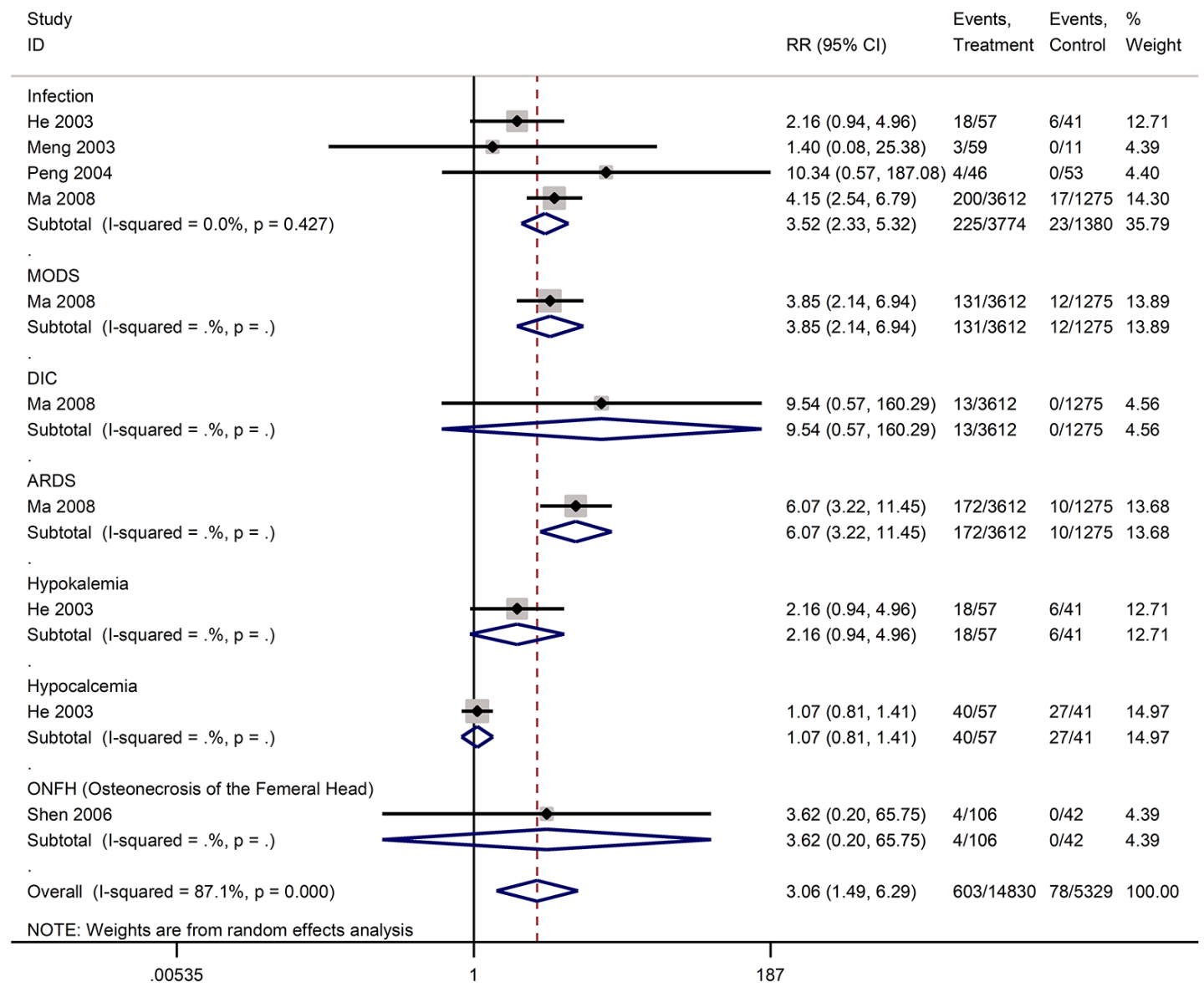

Figure 10 Relative risk of adverse events in patients receiving versus not receiving glucocorticoid therapy. RR, risk ratio; CI, confidence interval.

Table 4 GRADE evidence profile of COVID-19 studies

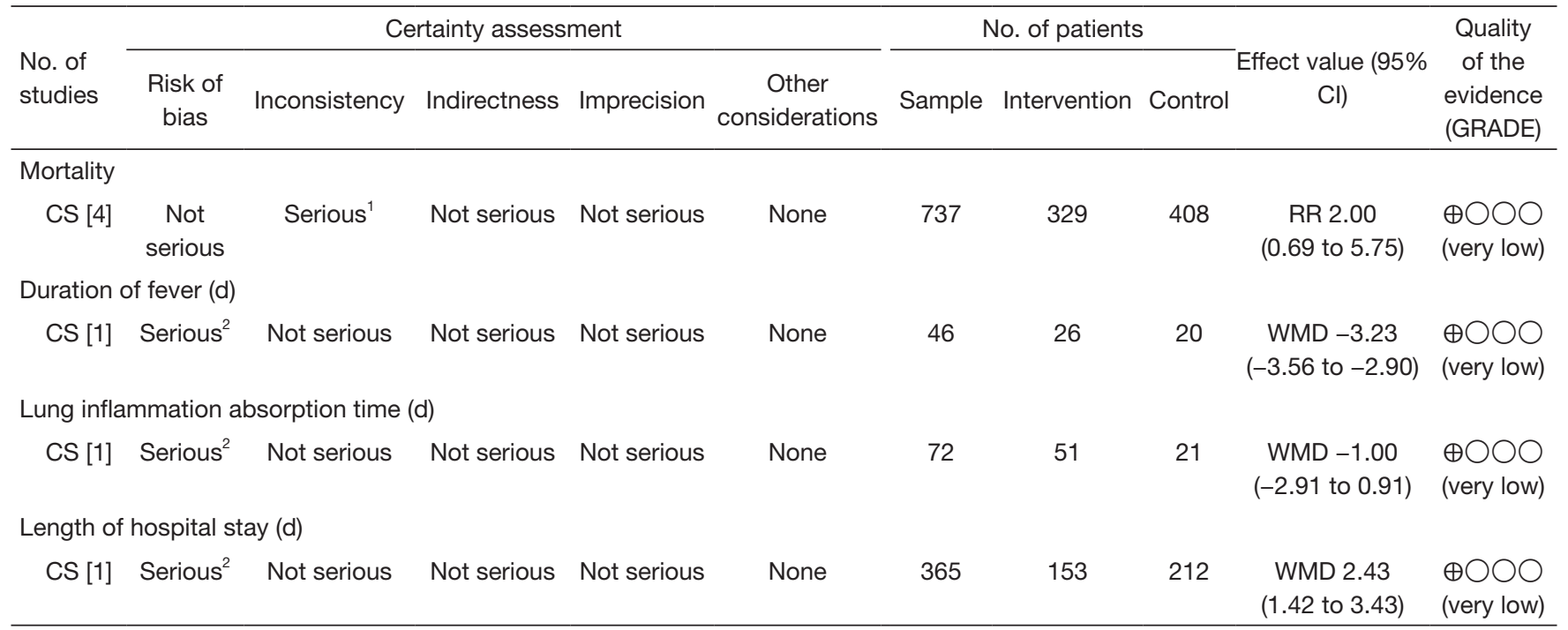

${ }^{1}$, downgrade one level: heterogeneity of data synthesis results, $\mathrm{I}^{2}>50 \%$; ${ }^{2}$, downgrade one level: the risk of bias is high due to the limitations of study design. RR, risk ratio; WMD, weighted mean difference; $\mathrm{Cl}$, confidence interval; CS, cohort study. 


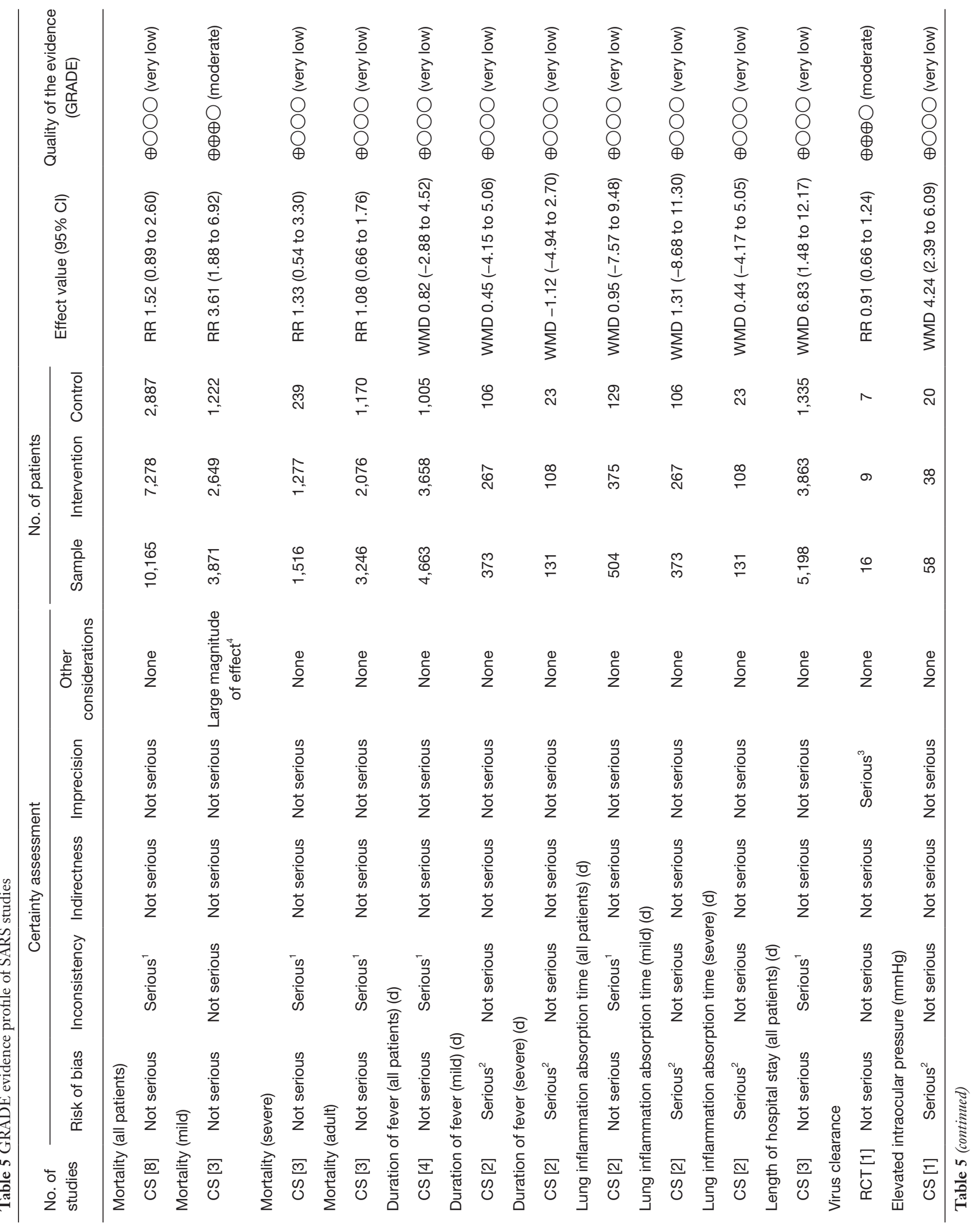




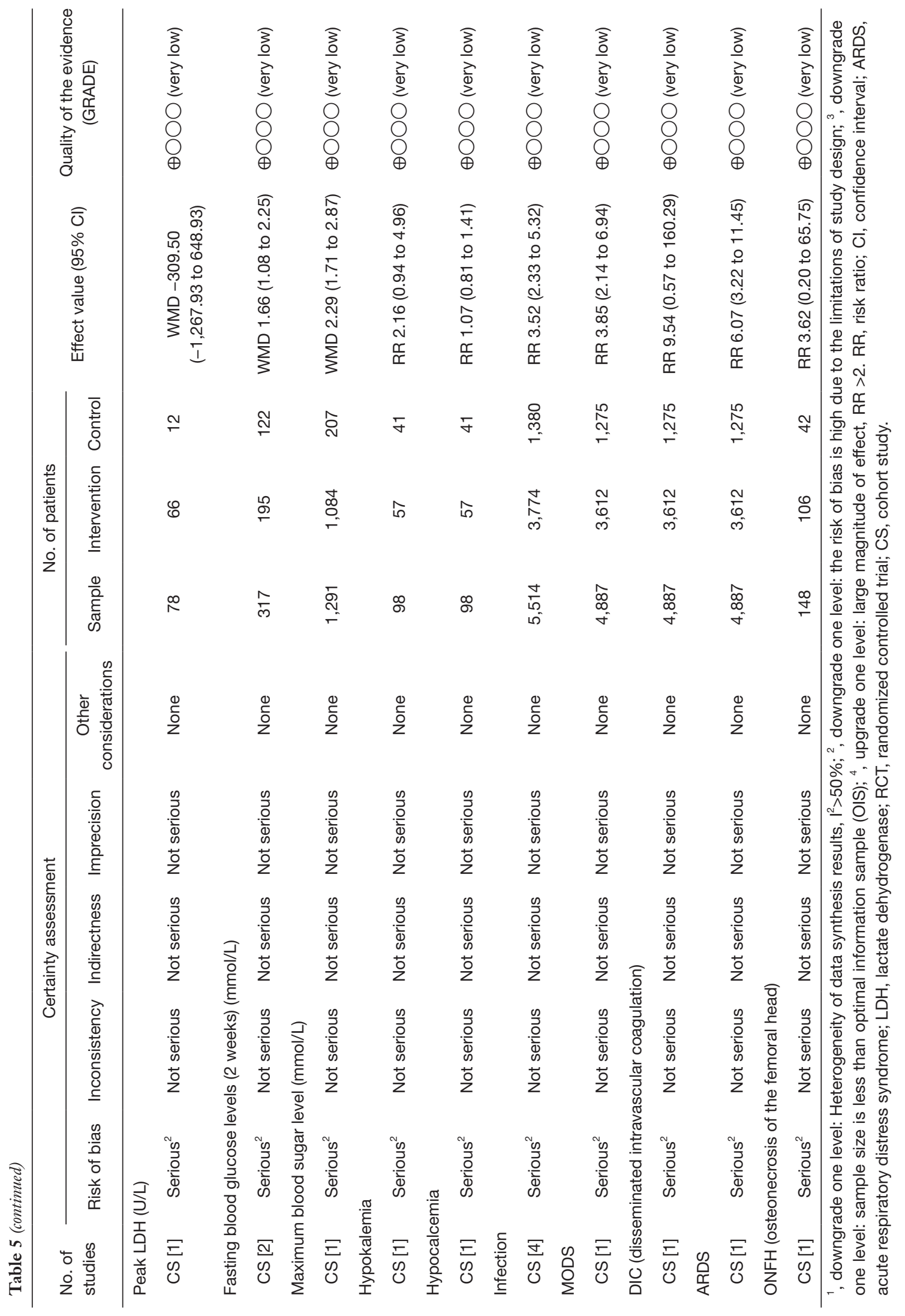


Table 6 GRADE evidence profile of MERS studies

\begin{tabular}{|c|c|c|c|c|c|c|c|c|c|c|}
\hline \multirow{2}{*}{$\begin{array}{l}\text { No. of } \\
\text { studies }\end{array}$} & \multicolumn{5}{|c|}{ Certainty assessment } & \multicolumn{3}{|c|}{ No. of patients } & \multirow{2}{*}{$\begin{array}{c}\text { Effect value } \\
(95 \% \mathrm{Cl})\end{array}$} & \multirow{2}{*}{$\begin{array}{l}\text { Quality } \\
\text { of the } \\
\text { evidence } \\
\text { (GRADE) }\end{array}$} \\
\hline & Risk of bias & Inconsistency & Indirectness & Imprecision & $\begin{array}{c}\text { Other } \\
\text { considerations }\end{array}$ & Sample & Intervention & Control & & \\
\hline \multicolumn{11}{|l|}{ Mortality } \\
\hline CS [1] & Not serious & Not serious & Not serious & Not serious & None & 309 & 151 & 158 & $\begin{array}{c}\text { RR } 1.29 \\
\text { (1.09 to } 1.52)\end{array}$ & $\begin{array}{c}\oplus \oplus \bigcirc \bigcirc \\
(\text { low })\end{array}$ \\
\hline CS [1] & Not serious & Not serious & Not serious & Not serious & None & 309 & 151 & 158 & $\begin{array}{c}\text { RR } 1.34 \\
\text { (1.14 to } 1.58)\end{array}$ & $\begin{array}{c}\oplus \oplus \bigcirc \bigcirc \\
(\text { low })\end{array}$ \\
\hline \multicolumn{11}{|c|}{ Hospital mortality } \\
\hline CS [1] & Not serious & Not serious & Not serious & Not serious & None & 309 & 151 & 158 & $\begin{array}{c}\text { RR } 1.33 \\
\text { (1.14 to } 1.56)\end{array}$ & $\begin{array}{c}\oplus \oplus \bigcirc \bigcirc \\
(\text { low })\end{array}$ \\
\hline CS [1] & Not serious & Not serious & Not serious & Not serious & None & 203 & 99 & 104 & $\begin{array}{c}\text { RR } 1.15 \\
\text { (0.77 to } 1.72)\end{array}$ & $\begin{array}{c}\oplus \oplus \bigcirc \bigcirc \\
(\text { low })\end{array}$ \\
\hline \multicolumn{11}{|c|}{ Length of hospital stay } \\
\hline CS [1] & Not serious & Not serious & Not serious & Serious $^{3}$ & None & 203 & 99 & 104 & $\begin{array}{c}\text { WMD } 6.30 \\
\text { (2.36 to } 10.24)\end{array}$ & $\begin{array}{l}\oplus \bigcirc \bigcirc \bigcirc \\
\text { (very low) }\end{array}$ \\
\hline
\end{tabular}

${ }^{3}$, downgrade one level: Sample size is less than optimal information sample (OIS). RR, risk ratio; Cl, confidence interval; WMD, weighted mean difference; CS, cohort study.

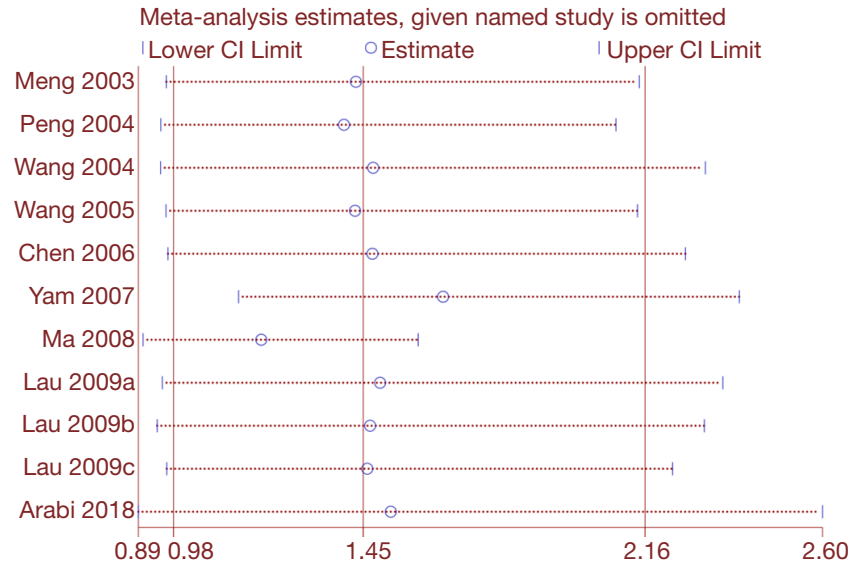

Figure 11 Sensitivity analysis of mortality in SARS patients.

quality showed that glucocorticoid therapy significantly reduced the duration of fever, but not the risk of death and lung inflammation absorption in patients with COVID-19 or SARS. In addition, glucocorticoid therapy may even prolong the duration of hospitalization. Long-term use of high-dose glucocorticoids increased the risk of adverse reactions such as infections and osteonecrosis. We found

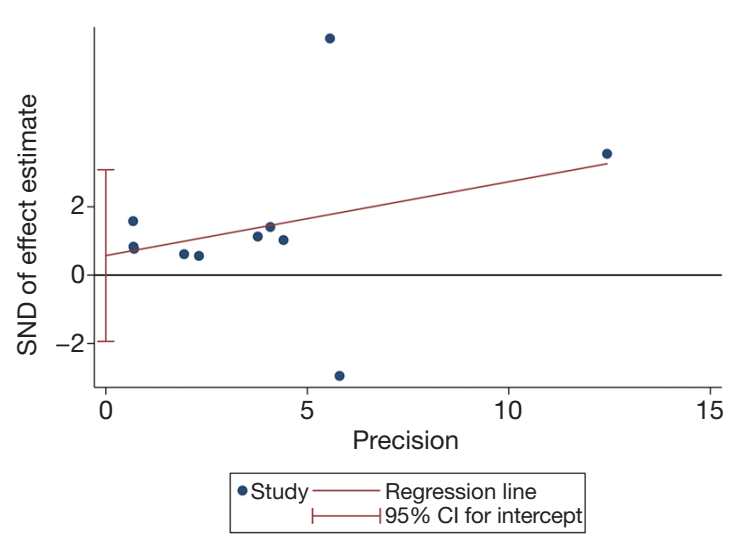

Figure 12 Publication bias (Egger test). SND, standard normal deviate; CI, confidence interval.

moderate-quality evidence that in patients with mild SARS glucocorticoids may be associated with a more than threefold increase in the risk of death.

Systemic glucocorticoids are highly effective antiinflammatory drugs, but their use against SARS-CoV-2 infection remains controversial. A case series of children with COVID-19 reported that systematic glucocorticoids 
(dose $2 \mathrm{mg} / \mathrm{kg}$ ) were given to both two included critical cases in combination with invasive mechanical ventilation and intravenous immunoglobulin. In both children, the symptoms on admission were alleviated, although in one of them only partly (52). A recent cohort study from $7 A M A$ Internal Medicine reported that among COVID-19 patients with ARDS, treatment with methylprednisolone decreased the risk of death (39). Our results are compared with published systematic reviews of glucocorticoid therapy for severe pneumonia. A recent rapid review of COVID-19 treatment showed controversial evidence on the use of corticosteroids, and could not give any suggestion on the use of corticosteroids due to the lack of quantitative synthesis (53). A systematic review covering in vitro studies on SARS, SARS in humans and other diseases such as ARDS, found that 25 of the 29 included studies were inconclusive, and the remaining four found glucocorticoids harmful (54). A recent systematic review of influenza pneumonia showed that glucocorticoid therapy increased the risk of death ( $\mathrm{RR}=1.75,95 \% \mathrm{CI}$ : $1.30,2.36)$, length of ICU stay (RR $=2.14$ days, $95 \%$ CI: $1.17,3.10)$, and risk of secondary infections ( $\mathrm{RR}=1.98,95 \% \mathrm{CI}: 1.04,3.78)$ (55). A meta-analysis of SARS in 2017 showed that the incidence of osteonecrosis increased with the dosing of systemic glucocorticoids, and the summary RR of osteonecrosis was 1.57 (95\% CI 1.30, 1.89) (56). As retrospective studies have shown that the glucocorticoids were given for $19 \%$ to $26 \%$ of patients with COVID-19 (and to $45 \%$ of patients with severe disease), there is a high risk that this therapy is currently misused (57-59). In summary, the current research evidence does not support the routine use of systemic glucocorticoids for patients with COVID-19. Because COVID-19 tends to be less severe in children than in adults (60), the use of systemic glucocorticoids should in particular not be recommended in children.

\section{Strengths and limitations}

This is to our knowledge the first comprehensive and systematic review of the effectiveness and safety of glucocorticoid therapy for patients with COVID-19 using data from the COVID-19 studies, and can be considered at the moment as the best evidence for decision-making on this topic. We conducted meta-analyses to quantitatively synthesize the findings of the included studies and objectively evaluate the current research evidence. Our study had also several limitations. We found only limited direct evidence of systemic glucocorticoids therapy for
COVID-19, and had to use indirect evidence from the SARS and MERS epidemics. We also could not conduct subgroup analyses according to the dose and type of glucocorticoids because of the small number of studies.

\section{Conclusions}

In conclusion, glucocorticoid therapy may increase the risk of death in patients with coronavirus infections who have mild symptoms. We found no association between glucocorticoids and mortality in patients with severe symptoms. In the context of clinical trials, low dose systemic glucocorticoid therapy for a short duration may be acceptable.

\section{Acknowledgments}

We thank Janne Estill, Institute of Global Health of University of Geneva for providing guidance and comments for our review. We thank all the authors for their wonderful collaboration.

Funding: This work was supported by grants from National Clinical Research Center for Child Health and Disorders (Children's Hospital of Chongqing Medical University, Chongqing, China) (grant number NCRCCHD-2020EP-01); Special Fund for Key Research and Development Projects in Gansu Province in 2020; The fourth batch of "Special Project of Science and Technology for Emergency Response to COVID-19" of Chongqing Science and Technology Bureau. Special funding for prevention and control of emergency of COVID-19 from Key Laboratory of Evidence Based Medicine and Knowledge Translation of Gansu Province (grant number No. GSEBMKT2020YJ01); The Fundamental Research Funds for the Central Universities (lzujbky-2020-sp14).

\section{Footnote}

Reporting Checklist: The authors have completed the PRISMA reporting checklist. Available at http://dx.doi. org/10.21037/atm-20-3307

Conflicts of Interest: All authors have completed the ICMJE uniform disclosure form (available at http://dx.doi. org/10.21037/atm-20-3307). MSL serves as the unpaid editorial board member of Annals of Translational Medicine from Nov 2019 to Oct 2021. The other authors have no conflicts of interest to declare. 
Ethical Statement: The authors are accountable for all aspects of the work in ensuring that questions related to the accuracy or integrity of any part of the work are appropriately investigated and resolved.

Open Access Statement: This is an Open Access article distributed in accordance with the Creative Commons Attribution-NonCommercial-NoDerivs 4.0 International License (CC BY-NC-ND 4.0), which permits the noncommercial replication and distribution of the article with the strict proviso that no changes or edits are made and the original work is properly cited (including links to both the formal publication through the relevant DOI and the license). See: https://creativecommons.org/licenses/by-nc-nd/4.0/.

\section{References}

1. Phelan AL, Katz R, Gostin LO. The Novel Coronavirus Originating in Wuhan, China: Challenges for Global Health Governance. JAMA 2020. [Epub ahead of print]. doi:10.1001/jama.2020.1097.

2. WHO Director-General's remarks at the media briefing on 2019-nCoV on 11 February 2020[Internet]. World Health Organization 2020 [cited 2020 Apr 13]. Available online: https://www.who.int/dg/speeches/detail/whodirector-general-s-remarks-at-the-media-briefing-on2019-ncov-on-11-february-2020

3. WHO characterizes COVID-19 as a pandemic. March 12, 2020[Internet]. World Health Organization 2020 [cited 2020 Apr 13]. Available online: https://www.who.int/ emergencies/diseases/novel-coronavirus-2019/events-asthey-happen

4. Coronavirus (COVID-19) [Internet]. World Health Organization 2020 [cited 2020 Apr 13]. Available online: https://who.sprinklr.com/

5. Lu R, Zhao X, Li J, et al. Genomic characterisation and epidemiology of 2019 novel coronavirus: implications for virus origins and receptor binding. Lancet 2020;395:565-74.

6. So LK, Lau AC, Yam LY, et al. Development of a standard treatment protocol for severe acute respiratory syndrome. Lancet 2003;361:1615-7.

7. Arabi YM, Al-Omari A, Mandourah Y, et al.; Saudi Critical Care Trial Group. Critically ill patients with the Middle East respiratory syndrome: a multicenter retrospective cohort study. Crit Care Med 2017;45:1683-95.

8. Russell CD, Millar JE, Baillie JK. Clinical evidence does not support corticosteroid treatment for 2019-nCoV lung injury. Lancet 2020;395:473-5.

9. Shang L, Zhao J, Hu Y, et al. On the use of corticosteroids for 2019-nCoV pneumonia. Lancet 2020;395:683-4.

10. Chen ZM, Fu JF, Shu Q, et al. Diagnosis and treatment recommendations for pediatric respiratory infection caused by the 2019 novel coronavirus. World J Pediatr 2020. [Epub ahead of print].

11. Jin YH, Cai L, Cheng ZS, et al. A rapid advice guideline for the diagnosis and treatment of 2019 novel coronavirus (2019-nCoV) infected pneumonia (standard version). Mil Med Res 2020;7:4.

12. Clinical management of severe acute respiratory infection (SARI) when COVID-19 disease is suspected [Internet]. World Health Organization March 2020 [cited 2020 Apr 13]. Available online: https://apps.who.int/iris/bitstream/ handle/10665/331446/WHO-2019-nCoV-clinical2020.4-eng.pdf

13. Novel Coronavirus(2019-nCoV) Situation Report - 33 [Internet]. World Health Organization 2020 [cited $2020 \mathrm{Apr}$ 13]. Available online: https://www.who.int/emergencies/ diseases/novel-coronavirus-2019/situation-reports

14. Li L, Tian J, Tian H, et al. Network meta-analyses could be improved by searching more sources and by involving a librarian. J Clin Epidemiol 2014;67:1001-7.

15. Moher D, Liberati A, Tetzlaff J, et al. Preferred reporting items for systematic reviews and meta-analyses: the PRISMA statement. PLoS Med 2009;6:e1000097.

16. Liberati A, Altman DG, Tetzlaff J, et al. The PRISMA statement for reporting systematic reviews and metaanalyses of studies that evaluate health care interventions: explanation and elaboration. PLoS Med 2009;6:e1000100.

17. Higgins JP, Altman DG, Gøtzsche PC, et al. The Cochrane Collaboration's tool for assessing risk of bias in randomised trials. BMJ 2011;343:d5928.

18. Stang A. Critical evaluation of the Newcastle-Ottawa scale for the assessment of the quality of nonrandomized studies in meta-analyses. Eur J Epidemiol 2010;25:603-5.

19. Guyatt G, Oxman AD, Akl EA, et al. GRADE guidelines: 1. Introduction-GRADE evidence profiles and summary of findings tables. J Clin Epidemiol 2011;64:383-94.

20. Norris SL, Meerpohl JJ, Akl EA, et al. The skills and experience of GRADE methodologists can be assessed with a simple tool. J Clin Epidemiol 2016;79:150-158.e1.

21. Guyatt GH, Oxman AD, Vist G, et al. GRADE guidelines: 4. Rating the quality of evidence--study limitations (risk of bias). J Clin Epidemiol 2011;64:407-15.

22. Guyatt GH, Oxman AD, Montori V, et al. GRADE guidelines: 5 . Rating the quality of evidence--publication 
bias. J Clin Epidemiol 2011;64:1277-82.

23. Guyatt GH, Oxman AD, Kunz R, et al. GRADE guidelines 6. Rating the quality of evidence--imprecision. J Clin Epidemiol 2011;64:1283-93.

24. Guyatt GH, Oxman AD, Kunz R, et al. GRADE guidelines: 7. Rating the quality of evidence--inconsistency. J Clin Epidemiol 2011;64:1294-302.

25. Guyatt GH, Oxman AD, Kunz R, et al. GRADE guidelines: 8. Rating the quality of evidence--indirectness. J Clin Epidemiol 2011;64:1303-10.

26. Guyatt GH, Oxman AD, Sultan S, et al. GRADE guidelines: 9. Rating up the quality of evidence. J Clin Epidemiol 2011;64:1311-6.

27. Cumpston M, Li T, Page MJ, et al. Updated guidance for trusted systematic reviews: a new edition of the Cochrane Handbook for Systematic Reviews of Interventions. Cochrane Database Syst Rev 2019;10:ED000142.

28. DerSimonian R, Kacker R. Random-effects model for meta-analysis of clinical trials: an update. Contemp Clin Trials 2007;28:105-14.

29. Meng QH, Dong P, Guo Y, et al. A preliminary study on the treatment of severe acute respiratory syndrome with glucocorticoid. Chinese Journal of Preventive Medicine 2003;37:233-5.

30. Peng J, Hou J, Guo Y, et al. Discussion on the treatment of SARS with glucocorticoid. Medical Journal of Chinese People's Liberation Army 2004;29:752-3.

31. Wang G, Li N, Wu Y, et al. Multifactor COX regression analysis of adrenal glucocorticoid use in patients with severe acute respiratory syndrome. Chin J Med 2004;84:1073-8.

32. Wang P, Li M, Shi Y, et al. (Evaluating the effects of different treatments on severe acute respiratory syndrome). Shanxi Medical Journal 2005;34:270-2.

33. Chen RC, Tang XP, Tan SY, et al. Treatment of severe acute respiratory syndrome with glucosteroids: the Guangzhou experience. Chest 2006;129:1441-52.

34. Yam LY, Lau A, Lai F, et al. Corticosteroid treatment of severe acute respiratory syndrome in Hong Kong. J Infect 2007;54:28-39.

35. Ma F. Study on the application value of glucocorticoid in the treatment of SARS. Huazhong University of Science and Technology, 2008.

36. Lau EH, Cowling BJ, Muller MP, et al. Effectiveness of ribavirin and corticosteroids for severe acute respiratory syndrome. Am J Med 2009;122:1150.e11-21.

37. Arabi YM, Mandourah Y, Al-Hameed F, et al. Corticosteroid Therapy for Critically Ill Patients with
Middle East Respiratory Syndrome. Am J Respir Crit Care Med 2018;197:757-67.

38. Zhou F, Yu T, Du R, et al. Clinical course and risk factors for mortality of adult inpatients with COVID-19 in Wuhan, China: a retrospective cohort study. Lancet 2020;395:1054-62. Erratum in: Department of Error. Lancet. 2020 Mar 28;395(10229):1038. doi: 10.1016/ S0140-6736(20)30606-1; Department of Error. Lancet. 2020 Mar 28;395(10229):1038. doi: 10.1016/S01406736(20)30638-3.

39. Wu C, Chen X, Cai Y, et al. Risk Factors Associated With Acute Respiratory Distress Syndrome and Death in Patients With Coronavirus Disease 2019 Pneumonia in Wuhan, China. JAMA Intern Med 2020. [Epub ahead of print]. doi: 10.1001/jamainternmed.2020.0994.

40. Wang Y, Jiang W, He Q, et al. Early, low-dose and shortterm application of corticosteroid treatment in patients with severe COVID-19 pneumonia: single-center experience from Wuhan, China. medRxiv 2020. [cited 2020 Apr 13] Available online: https://www.medrxiv.org/co ntent/10.1101/2020.03.06.20032342v1

41. Shang J, Du R, Lu Q, et al. The Treatment and Outcomes of Patients with COVID-19 in Hubei, China: A MultiCentered, Retrospective, Observational Study (2/26/2020). SSRN 2020 [cited 2020 Apr 13]. Available online: https:// papers.ssrn.com/sol3/papers.cfm?abstract_id=3546060

42. Ding K, Xu Z, Huang H, et al. Retrospective Analysis of the Glucocorticoid Treatment in 409 Patients with Severe Acute Respiratory Syndrome. Applied Journal of General Practice 2005;3:193-4.

43. Ni Q, Ding C, Li Y, et al. A retrospective study of virus clearance in patients with COVID-19 treated with low and medium-dose glucocorticoids. Chin J Clin Infect Dis 2020;13. doi: 10.3760/cma.j.cn115673-20200225-00072.

44. He R, Liu Z, Duan X. Adverse effects associated with corticosteroids therapy in 57 SARS cases. Adverse Drug Reactions Journal 2003;5:374-7.

45. Shen J, Liang B, Zeng Q, et al. MR imaging of proximal femoral bone marrow in patients with severe acute respiratory syndrome. Chin J Tuberc Respir Dis 2006;29:189-93.

46. Hu W, Wang L. Effect of glucocorticoid therapy upon glucose metabolism in SARS patients. Beijing Medical 2004;25:400-2.

47. Jin $\mathrm{M}$, Tong X, Wei $\mathrm{Y}$, et al. Observing the influence to the intraocular pressure of patients with severe acute respiratory syndrome. Journal of Traditional Chinese Ophthalmology 2004;14:7-9. 
48. Lee N, Allen Chan K, Hui D, et al. Effects of early corticosteroid treatment on plasma SARS-associated Coronavirus RNA concentrations in adult patients. J Clin Virol 2004;31:304-9.

49. Li N, Wang G, Wu Y, et al. Clinical diagnosis of SARS: analysis of adverse reactions to glucocorticoid therapy in 1291 cases. Journal of Peking University (Health Sciences) 2004;36:519-24.

50. Zhou Y, Zhang Y, Li Y, et al. Effect of short-term application of methylprednisolone on blood glucose level in patients with infectious SARS. Chinese Journal of Diabetes 2004;12:28-31.

51. Auyeung TW, Lee J, Lai W, et al. The use of corticosteroid as treatment in SARS was associated with adverse outcomes: a retrospective cohort study. J Infect 2005;51:98-102.

52. Zheng F, Liao C, Fan QH, et al. Clinical Characteristics of Children with Coronavirus Disease 2019 in Hubei, China. Curr Med Sci 2020;40:275-80.

53. Song Y, Zhang M, Yin L, et al. COVID-19 Treatment: Close to a Cure? - A Rapid Review of Pharmacotherapies for the Novel Coronavirus. Preprints 2020. doi: 10.20944/ preprints202003.0378.v1.

Cite this article as: Lu S, Zhou Q, Huang L, Shi Q, Zhao S, Wang Z, Li W, Tang Y, Ma Y, Luo X, Fukuoka T, Ahn HS, Lee MS, Luo Z, Liu E, Chen Y, Zhou C, Peng D; on behalf of COVID-19 Evidence and Recommendations Working Group. Effectiveness and safety of glucocorticoids to treat COVID-19: a rapid review and meta-analysis. Ann Transl Med 2020;8(10):627. doi: 10.21037/atm-20-3307
54. Stockman LJ, Bellamy R, Garner P. SARS: systematic review of treatment effects. PLoS Med 2006;3:e343.

55. Ni YN, Chen G, Sun J, et al. The effect of corticosteroids on mortality of patients with influenza pneumonia: a systematic review and meta-analysis. Critical Care 2019;23:99.

56. Zhao R, Wang H, Wang X, et al. Steroid therapy and the risk of osteonecrosis in SARS patients: a dose-response meta-analysis. Osteoporos Int 2017;28:1027-34.

57. Guan WJ, Ni ZY, Hu Y, et al. Clinical Characteristics of Coronavirus Disease 2019 in China. N Engl J Med 2020;382:1708-20.

58. $\mathrm{Xu} X W, \mathrm{Wu} X X$, Jiang $\mathrm{XG}$, et al. Clinical findings in a group of patients infected with the 2019 novel coronavirus (SARS-Cov-2) outside of Wuhan, China: retrospective case series. BMJ 2020;368:m606. Erratum in: BMJ. 2020 Feb 27;368:m792. doi: 10.1136/bmj.m792.

59. Huang C, Wang Y, Li X, et al. Clinical features of patients infected with 2019 novel coronavirus in Wuhan, China. Lancet 2020;395:497-506.

60. Dong Y, Mo X, Hu Y, et al. Epidemiological characteristics of 2143 pediatric patients with 2019 coronavirus disease in China. Pediatrics 2020. doi: 10.1542/peds.2020-0702. 


\section{Supplementary material 1 Search strategy}

\section{PubMed}

\#1. $\quad$ "COVID-19"[Supplementary Concept]

\#2. "Severe Acute Respiratory Syndrome Coronavirus 2"[Supplementary Concept]

\#3. $\quad$ "Middle East Respiratory Syndrome Coronavirus"[Mesh]

\#4. "Severe Acute Respiratory Syndrome"[Mesh]

\#5. $\quad$ "SARS Virus"[Mesh]

\#6. $\quad$ "COVID-19"[Title/Abstract]

\#7. $\quad$ "SARS-COV-2"[Title/Abstract]

\#8. "Novel coronavirus"[Title/Abstract]

\#9. "2019-novel coronavirus"[Title/Abstract]

\#10. "coronavirus disease-19"[Title/Abstract]

\#11. "coronavirus disease 2019"[Title/Abstract]

\#12. $\quad$ "COVID 19"[Title/Abstract]

\#13. "Novel CoV"[Title/Abstract]

\#14. "2019-nCoV"[Title/Abstract]

\#15. "2019-CoV"[Title/Abstract]

\#16. "Middle East Respiratory Syndrome"[Title/Abstract]

\#17. "MERS"[Title/Abstract]

\#18. "MERS-CoV"[Title/Abstract]

\#19. "Severe Acute Respiratory Syndrome"[Title/Abstract]

\#20. "SARS"[Title/Abstract]

\#21. "SARS-CoV"[Title/Abstract]

\#22. "SARS-Related"[Title/Abstract]

\#23. "SARS-Associated"[Title/Abstract]

\#24. \#1-\#23/ OR

\#25. "adrenal cortex hormones"[Mesh]

\#26. "Beclomethasone"[Title/Abstract]

\#27. " betamethasone valerate "[Mesh]

\#28. "Budesonid"[Title/Abstract]

\#29. "Cortodoxone"[Title/Abstract]

\#30. "Dexamethasone"[Title/Abstract]

\#31. "glucocorticoids"[ Mesh]

\#32. "Hydrocortisone"[Title/Abstract]

\#33. "Hydroxycorticosteroids"[Title/Abstract]

\#34. "methylprednisolone"[Mesh]

\#35. "adrenal cortex hormone*"[Title/Abstract]

\#36. "becl?met*"[Title/Abstract]

\#37. "betamet?asone*"[Title/Abstract]

\#38. "budesonide*"[Title/Abstract]

\#39. "clobetasol*"[Title/Abstract]

\#40. "corticoid*"[Title/Abstract]

\#41. "corticosteroid*"[Title/Abstract]

\#42. "corticosterone*"[Title/Abstract]

\#43. "cortisone*"[Title/Abstract]

\#44. "cortodoxone*"[Title/Abstract]

\#45. "dexamet?asone*"[Title/Abstract] 
\#46. "glucocortico*"[Title/Abstract]

\#47. "hydrocortisone*"[Title/Abstract]

\#48. "hydroxycorticosteroid*"[Title/Abstract]

\#49. "hydroxypregnenolone*"[Title/Abstract]

\#50. "methylprednisolone*"[Title/Abstract]

\#51. "prednisolone*"[Title/Abstract]

\#52. "prednisone*"[Title/Abstract]

\#53. "pregnenedione*"[Title/Abstract]

\#54. "pregnenolone*"[Title/Abstract]

\#55. "tetrahydrocortisol*"[Title/Abstract]

\#56. "triamcinolone*"[Title/Abstract]

\#57. \#25-\#56/ OR

\#58. \#24 AND \#57

\section{EMBASE}

\#1. 'middle east respiratory syndrome coronavirus'/exp

\#2. $\quad$ 'severe acute respiratory syndrome'/exp

\#3. 'sars coronavirus'/exp

\#4. 'COVID-19':ab,ti

\#5. 'SARS-COV-2':ab,ti

\#6. 'novel coronavirus':ab,ti

\#7. '2019-novel coronavirus':ab,ti

\#8. 'coronavirus disease-19':ab,ti

\#9. 'coronavirus disease 2019':ab,ti

\#10. 'COVID 19':ab,ti

\#11. 'novel cov':ab,ti

\#12. '2019-ncov':ab,ti

\#13. '2019-cov':ab,ti

\#14. 'middle east respiratory syndrome':ab,ti

\#15. 'middle east respiratory syndrome coronavirus':ab,ti

\#16. 'mers':ab,ti

\#17. 'mers-cov':ab,ti

\#18. 'severe acute respiratory syndrome':ab,ti

\#19. 'sars':ab,ti

\#20. 'sars-cov':ab,ti

\#21. 'sars-related':ab,ti

\#22. 'sars-associated':ab,ti

\#23. \#1-\#22/ OR

\#24. 'glucocorticoid'/exp

\#25. 'methylprednisolone'/exp

\#26. 'cortisone'/exp

\#27. 'dexamethasone'/exp

\#28. 'prednisone'/exp

\#29. 'betamethasone'/exp

\#30. 'glucocorticoid*':ab,ti

\#31. 'methylprednisolone*':ab,ti

\#32. 'cortisone*':ab,ti 
\#33. 'dexamethasone ${ }^{* 1}: a b, t i$

\#34. 'prednisone*':ab,ti

\#35. 'budesonid*':ab,ti

\#36. 'hexadecadrol':ab,ti

\#37. 'cortodoxone':ab,ti

\#38. 'hydrocortisone':ab,ti

\#39. 'hydroxycorticosteroids':ab,ti

\#40. 'adrenal cortex hormone*':ab,ti

\#41. 'becl?met*':ab,ti

\#42. 'betamet?asone*':ab,ti

\#43. 'clobetasol*':ab,ti

\#44. 'corticoid*':ab,ti

\#45. 'corticosteroid*':ab,ti

\#46. 'corticosterone': ab,ti

\#47. 'cortodoxone*':ab,ti

\#48. 'dexamet?asone*':ab,ti

\#49. 'glucocortico*':ab,ti

\#50. 'hydrocortisone*':ab,ti

\#51. 'hydroxycorticosteroid*':ab,ti

\#52. 'hydroxypregnenolone*':ab,ti

\#53. 'prednisolone*':ab,ti

\#54. 'pregnenedione*':ab,ti

\#55. 'pregnenolone*':ab,ti

\#56. 'tetrahydrocortisol*':ab,ti

\#57. 'triamcinolone*':ab,ti

\#58. \#24-\#57/ OR

\#59. \#23 AND \#58

\#60. \#59 lim(embase)

\section{Cochrane}

\#1. MeSH descriptor: (Middle East Respiratory Syndrome Coronavirus) explode all trees

\#2. MeSH descriptor: (Severe Acute Respiratory Syndrome) explode all trees

\#3. MeSH descriptor: (SARS Virus) explode all trees

\#4. "COVID-19":ti,ab,kw

\#5. "SARS-COV-2":ti,ab,kw

\#6. "Novel coronavirus":ti,ab,kw

\#7. $\quad$ "2019-novel coronavirus":ti,ab,kw

\#8. $\quad$ "Novel CoV":ti,ab,kw

\#9. "2019-nCoV":ti,ab,kw

\#10. "2019-CoV":ti,ab,kw

\#11. "coronavirus disease-19":ti,ab,kw

\#12. "coronavirus disease 2019":ti,ab,kw

\#13. "COVID 19":ti,ab,kw

\#14. "Middle East Respiratory Syndrome":ti,ab,kw

\#15. "MERS":ti,ab,kw

\#16. "MERS-CoV":ti,ab,kw

\#17. "Severe Acute Respiratory Syndrome":ti,ab,kw 
\#18. $\quad$ "SARS":ti,ab,kw

\#19. "SARS-CoV":ti,ab,kw

\#20. "SARS-Related":ti,ab,kw

\#21. "SARS-Associated":ti,ab,kw

\#22. \#1-\#21/ OR

\#23. MeSH descriptor: (Glucocorticoids) explode all trees

\#24. MeSH descriptor: (Methylprednisolone) explode all trees

\#25. MeSH descriptor: (Cortisone) explode all trees

\#26. MeSH descriptor: (Dexamethasone) explode all trees

\#27. MeSH descriptor: (Prednisone) explode all trees

\#28. MeSH descriptor: (Budesonide) explode all trees

\#29. MeSH descriptor: (Betamethasone) explode all trees

\#30. "Adrenal Cortex Hormones":ti,ab,kw

\#31. "Glucocorticoid*":ti,ab,kw

\#32. "methylprednisolone*":ti,ab,kw

\#33. "cortisone*":ti,ab,kw

\#34. "Dexamethasone*":ti,ab,kw

\#35. "prednisone*":ti,ab,kw

\#36. "budesonid*":ti,ab,kw

\#37. "Beclomethasone":ti,ab,kw

\#38. "hexadecadrol":ti,ab,kw

\#39. "adrenal cortex hormone*":ti,ab,kw

\#40. "becl?met*":ti,ab,kw

\#41. "betamet?asone*":ti,ab,kw

\#42. "clobetasol*":ti,ab,kw

\#43. "corticoid*":ti,ab,kw

\#44. "corticosteroid*":ti,ab,kw

\#45. "corticosterone*":ti,ab,kw

\#46. "cortodoxone*":ti,ab,kw

\#47. "dexamet?asone*":ti,ab,kw

\#48. "glucocortico*":ti,ab,kw

\#49. "hydrocortisone*":ti,ab,kw

\#50. "hydroxycorticosteroid*":ti,ab,kw

\#51. "hydroxypregnenolone*":ti,ab,kw

\#52. "prednisolone*":ti,ab,kw

\#53. "pregnenedione*":ti,ab,kw

\#54. "pregnenolone*":ti,ab,kw

\#55. "tetrahydrocortisol*" :ti,ab,kw

\#56. "triamcinolone*":ti,ab,kw

\#57. \#23-\#56/ OR

\#58. \#22 AND \#57

\section{Web of Science}

\#1 TOPIC: "COVID-19"

\#2 TOPIC: "SARS-COV-2"

\#3 TOPIC: "Novel coronavirus"

\#4 TOPIC: "2019-novel coronavirus" 


\begin{tabular}{|c|c|}
\hline \#5 & TOPIC: "coronavirus disease-19" \\
\hline \#6 & TOPIC: "coronavirus disease 2019" \\
\hline \#7 & TOPIC: "COVID 19" \\
\hline$\# 8$ & TOPIC: "Novel CoV" \\
\hline$\# 9$ & TOPIC: "2019-nCoV" \\
\hline \#10 & TOPIC: "2019-CoV" \\
\hline \#11 & TOPIC: "Middle East Respiratory Syndrome" \\
\hline$\# 12$ & TOPIC: "MERS" \\
\hline$\# 13$ & TOPIC: "MERS-CoV" \\
\hline$\# 14$ & TOPIC: "Severe Acute Respiratory Syndrome" \\
\hline \#15 & TOPIC: "SARS" \\
\hline$\# 16$ & TOPIC: "SARS-CoV" \\
\hline$\# 17$ & TOPIC: "SARS-Related" \\
\hline \#18 & TOPIC: "SARS-Associated" \\
\hline \#19 & $\# 1-\# 18 /$ OR \\
\hline$\# 20$ & TOPIC: "methylprednisolone*" \\
\hline$\# 21$ & TOPIC: "cortisone*" \\
\hline$\# 22$ & TOPIC: "Dexamethasone*" \\
\hline$\# 23$ & TOPIC: "prednisone*" \\
\hline$\# 24$ & TOPIC: "budesonid*" \\
\hline$\# 25$ & TOPIC: "Beclomethasone" \\
\hline \#26 & TOPIC: "hexadecadrol*" \\
\hline$\# 27$ & TOPIC: "adrenal cortex hormone*" \\
\hline \#28 & TOPIC: "becl?met*" \\
\hline$\# 29$ & TOPIC: "betamet?asone*" \\
\hline$\# 30$ & TOPIC: "clobetasol*" \\
\hline \#31 & TOPIC: "corticoid*" \\
\hline \#32 & TOPIC: "corticosteroid*" \\
\hline \#33 & TOPIC: "corticosterone*" \\
\hline \#34 & TOPIC: "cortodoxone*" \\
\hline \#35 & TOPIC: "dexamet?asone*" \\
\hline \#36 & TOPIC: "glucocortico*" \\
\hline \#37 & TOPIC: "hydrocortisone*" \\
\hline \#38 & TOPIC: "hydroxycorticosteroid*" \\
\hline \#39 & TOPIC: "hydroxypregnenolone*" \\
\hline$\# 40$ & TOPIC: "prednisolone*" \\
\hline \#41 & TOPIC: "pregnenedione*" \\
\hline$\# 42$ & TOPIC: "pregnenolone*" \\
\hline \#43 & TOPIC: "tetrahydrocortisol*" \\
\hline$\# 44$ & TOPIC: "triamcinolone*" \\
\hline$\# 45$ & \#20-\#44 OR \\
\hline \#46 & \#19 AND \#45 \\
\hline
\end{tabular}

\section{CBM}

\#1 "新型冠状病毒"(常用字段:智能)

\#2 "COVID-19"(常用字段:智能)

\#3 "COVID 19"(常用字段:智能) 


\begin{tabular}{|c|c|}
\hline \#4 & "2019-nCoV"(常用字段:智能) \\
\hline \#5 & "2019-CoV"(常用字段:智能) \\
\hline$\# 6$ & "SARS-CoV-2"(常用字段:智能) \\
\hline \#7 & "中东呼吸综合征冠状病毒"(不加权:扩展) \\
\hline \#8 & "中东呼吸综合征"(常用字段:智能) \\
\hline$\# 9$ & "MERS"(常用字段:智能) \\
\hline$\# 10$ & "MERS-CoV"(常用字段:智能) \\
\hline \#11 & "严重急性呼吸综合征"(不加权:扩展) \\
\hline$\# 12$ & "SARS病毒"(不加权:扩展) \\
\hline$\# 13$ & "严重急性呼吸综合征"(常用字段:智能) \\
\hline \#14 & "SARS"(常用字段:智能) \\
\hline \#15 & $\# 1-\# 14 /$ OR \\
\hline \#16 & "糖皮质激素"(不加权:扩展) \\
\hline \#17 & "糖皮质激素"(常用字段:智能) \\
\hline$\# 18$ & "可的松" (常用字段:智能) \\
\hline \#19 & "布地奈德"(常用字段:智能) \\
\hline$\# 20$ & "地塞米松"(常用字段:智能) \\
\hline$\# 21$ & "强的松"(常用字段:智能) \\
\hline$\# 22$ & "泼尼松"(常用字段:智能) \\
\hline$\# 23$ & "甲泼尼龙"(常用字段:智能) \\
\hline$\# 24$ & "甲强龙"(常用字段:智能) \\
\hline \#25 & $\# 16-\# 24 / \mathrm{OR}$ \\
\hline \#26 & \#15 AND \#25 \\
\hline
\end{tabular}

\section{WanFang}

$\begin{array}{ll}\# 1 & \text { "新型冠状病毒"(主题) } \\ \# 2 & \text { "COVID-19"(主题) } \\ \# 3 & \text { "COVID 19"(主题) } \\ \# 4 & \text { "2019-nCoV"(主题) } \\ \# 5 & \text { "2019-CoV"(主题) } \\ \# 6 & \text { "SARS-CoV-2"(主题) } \\ \# 7 & \text { "中东呼吸综合征"(主题) } \\ \# 8 & \text { "MERS"(主题) } \\ \# 9 & \text { "MERS-CoV"(主题) } \\ \# 10 & \text { "严重急性呼吸综合征"(主题) } \\ \# 11 & \text { "SARS"(主题) } \\ \# 12 & \text { \#1-\#11/ OR } \\ \# 13 & \text { "糖皮质激素"(主题) } \\ \# 14 & \text { "泼尼松"(主题) } \\ \# 15 & \text { "强的松"(主题) } \\ \# 16 & \text { "布地奈德"(主题) } \\ \# 17 & \text { "地塞米松"(主题) } \\ \# 18 & \text { "可的松"(主题) } \\ \# 19 & \text { "甲泼尼龙"(主题) } \\ \text { \#20 } & \text { "甲强龙"(主题) } \\ \# 21 & \text { \#13-\#20/OR } \\ \# 22 & \text { \#12 AND \#21 }\end{array}$




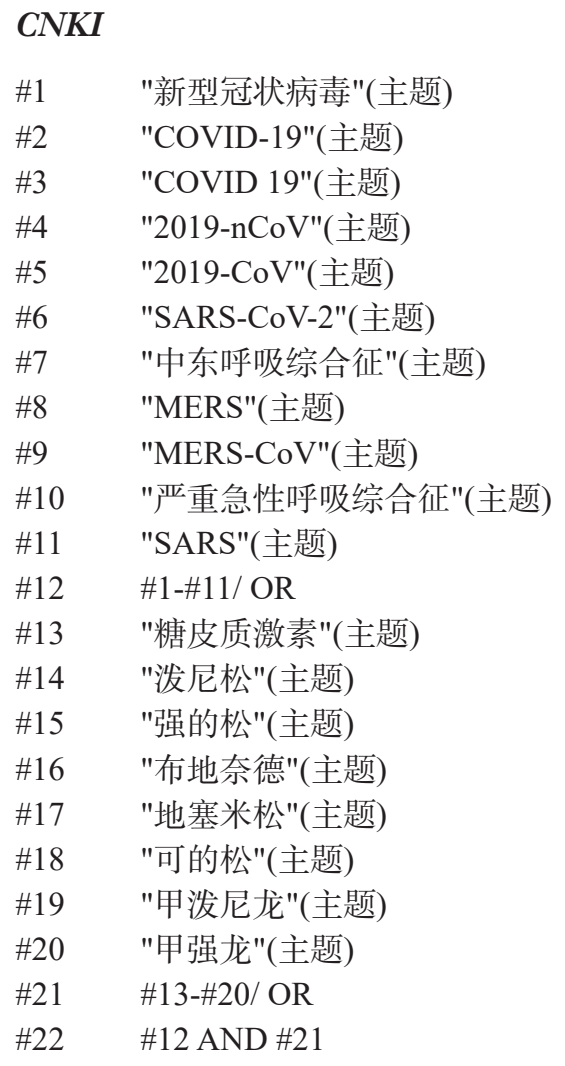

